\title{
Juegos infantiles en los ciclos de las Edades de la vida. Una conquista de la pintura europea entre los siglos XIV y XVII
}

\author{
Oriol Vaz-Romero Trueba \\ Universitat de Barcelona. Departament d'Arts i Conservació-Restauració \\ ovaztrueba@gmail.com
}

Recepción: 31/03/2020, Aceptación: 03/08/2020, Publicación: 28/12/2020

\begin{abstract}
Resumen
La representación de los juegos infantiles despuntó en el arte clásico. Sin embargo, hay que esperar hasta el siglo XIV para que surja un renovado interés por las escenas relacionadas con la infancia. Este «despertar» iconográfico irrumpió en el ciclo de las edades de la vida a través de manuscritos y pinturas murales. Ejemplo de ello son los frescos de Longthorpe Tower en Inglaterra ( 1330 ) y ciertas pinturas murales de temática profana en Italia entre I 360 y I 524 . Dichas pinturas sirvieron de modelo para nuevas imágenes en las enciclopedias y en los tratados morales. A partir del siglo XV la iconografía multiplicó el número y la especificidad de los juguetes, pero conquistó también nuevos soportes - tapices, objetos mobiliarios, pinturas sobre tabla y lienzo, así como emblemas xilográficos y estampas-. Las Edades se convirtieron en el centro de un complejo debate sobre los beneficios y los peligros del juego en la educación moral del hombre, al tiempo que su presencia en el arte y la literatura revelaba una creciente conciencia sobre la infancia, una edad con derecho propio en la cultura de los adultos.
\end{abstract}

Palabras clave:

juegos y juguetes; infancia; edades de la vida; pintura; arte occidental; siglos xIV-xVII

Abstract

Children's games in the Ages of Man cycles: Conquering European painting from the i 4 th to the I 7 th centuries

Although the depiction of children's games first emerged in classical art, it would not be until the i 4 th century when interest arose in profane scenes related to childhood. This iconographic "awakening" appeared in the cycle of the ages of life through mural paintings and manuscripts. Examples of this include the Longthorpe Tower wall paintings ( 1330 ) and some profane frescoes in Italian palaces and churches dating from $\mathrm{I} 360$ and I 524 . These works served as a model for new images in encyclopedias and moral treatises. From the is th century, the iconography of children's games was also depicted in other media, such as tapestries, furniture, paintings on panel and canvas, as well as woodcut emblems and prints. The Ages of Man iconography became the center of a complex debate on the benefits and dangers of play in man's moral education, while revealing a growing collective consciousness about childhood as an age in its own right.

Keywords:

games and toys; childhood; ages of life; painting; Western art; I 4 th-I 7 th centuries 
$\mathrm{E}$ 1 hombre ha sabido siempre que su paso por la Tierra es limitado y que nada puede hacer para detener el tiempo. Consecuencia de tan mayúscula certeza es el conjunto de imaginarios asociados al ciclo de las Edades de la vida, que se convirtió en uno de los más fecundos de la cultura occidental. Dicho ciclo no solo abarca la medicina, la filosofía moral, la pedagogía y la alquimia, sino también la esfera de las artes visuales como síntesis de todos los conocimientos anteriores. Recuerda el filósofo Julián Marías que la vida es continua desde el nacimiento hasta la muerte, pero que está articulada en «épocas naturales» o edades ${ }^{1}$. A su vez, Romano Guardini describe la existencia terrenal como una realidad fluyente dividida en etapas cerradas en sí mismas². El significado de cada una de dichas etapas es precisamente lo que las sucesivas culturas han tratado de definir. La infancia ocupa un lugar destacado entre todas ellas y, en el ámbito iconográfico, se reviste de figuras y atributos que permiten distinguir la edad de los juegos de las edades del adulto.

Son muchos los estudiosos ${ }^{3}$ que han analizado el número y el significado de las Ætates hominum a partir de las fuentes clásicas y medievales: cuatro, seis, siete y hasta doce según las fuentes. Sin embargo, en su Medicina Escéptica (1722-1725), el filósofo madrileño Martín Martínez bromeaba sobre la complejidad de semejante tarea. Quiso zanjar la discusión sobre «que sean las edades y cuantas» diciendo por boca de un filósofo hipocrático:

No gastéis tiempo en esso pues según los fines que se han propuesto los Autores, han dividido tan variadamente las edades, que apenas hay numero, que no tenga su proteccion: tal vez Edad se toma por Ævitas y esto es todo el curso de la vida; tal vez por los dos extremos:
Mozo, y Viejo; tal vez por los tres estados de Aristoteles; tal por quatro con Hippocrates, tal por cinco con Platon, que en sentido moral dividiò la vida en cinco partes; otros dàn seis edades, otros ocho partiendo la vejèz en vejèz, y decrepitud, y la menor edad en infancia, y puericia, y también es de Hippocrates esta division; los Astrologos dàn siete por la fingida correspondencia à los Planetas; ay quien de siete en siete años admite una edad y hasta doce edades no faltan patronos ${ }^{4}$.

A pesar de las diferencias habidas entre los autores de la Antigüedad pagana y del cristianismo medieval, la mayoría coincidió en subdividir la actual noción de infancia al menos en dos edades distintas: infantia y pueritia. Este hecho apenas ha suscitado el interés entre los autores modernos $^{5}$ y escasean aún más los estudios sobre su resonancia en la arquitectura y las artes visuales. En anteriores trabajos ya señalamos que la representación artística del niño y su mundo no es una cuestión menor, sino una verdadera fuente de conocimiento acerca del modo en que la sociedad ha comprendido la totalidad del hombre en cada momento de la historia ${ }^{6} \cdot{ }^{\circ}$ Cuándo surgen las primeras representaciones de las edades y con qué atributos para la infancia? ¿De qué modo arraigó este imaginario profano en la cultura cristiana?

\section{Pueritia e infantia: primeras edades del hombre en el pensamiento medieval}

Según Pitágoras, cuatro eran las divisiones de la vida, en correspondencia con las cuatro estaciones del año, atribuyendo a cada una de ellas una duración de veinte años?. Dicha partición 
caló en autores latinos como Ovidio y Cicerón8, pero también en la tradición médica griega, que lo relacionó con los cuatro humores'. Hipócrates afirmaba que el niño es húmedo y caliente, en contraposición al anciano, seco y frío. La teoría humoral se difundió en el Occidente medieval a partir de varias traducciones de Galeno y de los Aforismos hipocráticos, como el Liber Pantegni de Haly Abbas, latinizado en el siglo XI por Constantino el Africano, y el Canon de Avicena, traducido un siglo después por Gerardo de Cremona. Para el médico persa, los quince años que duraba la infancia quedaban subdivididos en infantia - de los o a los 7 años - y en pueritia - de los 7 a los I4 años-, recuperando así una división latina atribuida a Marco Terencio Varrón ${ }^{10}$.

Las teorías hipocráticas sobre las edades rebasaron los primeros siglos de cristianismo en compañía de otras divisiones afines. El esquema de los meses y las estaciones del año representaba la primavera, desde el reinado de Adriano ( I I7-I 38 d. C.), mediante putti juguetones. Así lo reflejan diversos sarcófagos de época ${ }^{11}$. En el siglo II, Antíoco de Atenas propició un modelo basado en los signos del zodiaco ${ }^{12}$, mientras que Ptolomeo afirmaba que el crecimiento del hombre está regido por los siete planetas conocidos. En su Tetrabiblos se establece claramente que la Luna rige sobre la primera edad ${ }^{13}$; mientras que Mercurio tutela la pubertad y Venus reina sobre la adolescencia; el Sol lo hace sobre la juventud y Marte, sobre la edad viril. En el ocaso de la vida, Júpiter influye sobre la vejez y Saturno, sobre la decrepitud. La arquitectura gótica propició no pocos sincretismos entre las teorías zodiacal y astronómica, como demuestran en particular los capiteles del Palacio Ducal de Venecia ${ }^{14}$.

Los eruditos de la Universitas Christiana ordenaron el ritmo de la vida a partir de la naturaleza, primera fuente de la revelación divina, concibiendo el cuerpo humano como un cosmos en miniatura. Según el neoplatónico Guillermo de Conches:

Elhombre recibe en griego el nombre de microcosmos, es decir pequeño mundo, porque su cabeza tiene una forma redondeada, como una esfera, en la cual sus dos ojos brillan como el sol y la luna [...]. Está dotado de razón, como los ángeles, que es lo que le hace inmortal. Puesto que el hombre es un microcosmos, no es indigno comparar la rueda del nacimiento humano con el movimiento del tiempo ${ }^{15}$.

De este modo, se incorporó el esquema pagano de las cuatro edades al simbolismo bíblico del número $4^{16}$. Según Alberto Magno, durante la primera edad, el hombre es infirme por naturaleza y acumula sustancia y fuerza ${ }^{17}$. Influido por este esquema, el pedagogo Philippe de Novare (ca. I 265) asociaba la enfance a un tiempo peligroso debido al exceso de jeu y joie $e^{18}$.

No faltaron actualizaciones del diseño cuaternario con los escritos de Orígenes y de Gregorio Magno, proseguidas por los autores del renacimiento carolingio. Entonces, la vida humana habría de pasar por seis edades, a semejanza de las edades del mundo: Adán, Noé, Abraham, David, Babilonia y Cristo. Mientras que los autores griegos parecían ajenos a dicha división, san Agustín propuso el número 6 para su modelo, recuperando así la tradición hebrea, según la cual existe una relación directa entre las seis edades del mundo y los seis días de la creación ${ }^{19}$. Autores sucesivos como Dracontio, Eugenio de Toledo y sobre todo Isidoro de Sevilla ${ }^{20}$ aseguraron el éxito de este esquema adaptándolo al número 7. Entrado el siglo XIII, la división agustiniana e isidoriana fue confirmada por autores tan dispares como Honorio de Autun y Lamberto de Saint-Omer, seguidos por lexicógrafos y escolásticos de la talla de Juan de Gales, Uguccio de Pisa, Juan Balbo de Génova y Bartolomeo Ánglico, sobre el que nos detendremos más adelante habida cuenta de los modelos iconográficos que propició.

\section{El juego infantil: un dilema moral en las fuentes literarias}

El vocabulario medieval no es menos abigarrado en lo relativo a la infancia. Para designar al niño se utilizaban términos como infans, puer, puella, parvulus y juvenis ${ }^{21}$, y en castellano antiguo, joven, ninno y ninya $a^{22}$. Algunos textos jurídicos se refieren a «niños de dieciocho y veinticinco años» y algunas reglas monásticas mencionan a infantulus de doce años. Nos topamos con expresiones como aetas proxima infantiae -formada por dos períodos consecutivos - y pueritia - también partida en dos fases: aetas proxima pubertatis y el puer grandisculus -, pudiendo distinguir no ya dos, sino tres y cuatro fases infantiles ${ }^{23}$. En todas ellas, el niño aparece como una misteriosa «figura de $\operatorname{cera}^{24}{ }^{24}$ que debe ser moldeada cuanto antes. Hasta los dos años es la edad tenera del destete y del crecimiento de los dientes. Es una criatura qui non fari potest, que no sabe hablar. De los dos a los siete años, el infans se rige por sus deseos. Para santo Tomás, roza así el mundo de los $\operatorname{locos}^{25}$, pues ambas criaturas están regidas por los poderes oscuros de la Luna. Todos, el niño, el hombre salvaje y el loco son «lunáticos» de acuerdo con el modelo ptolemaico ya citado. La tercera fase o pueritia alcanza los doce años: es la edad de la diferenciación sexual y de aprender a orar, 


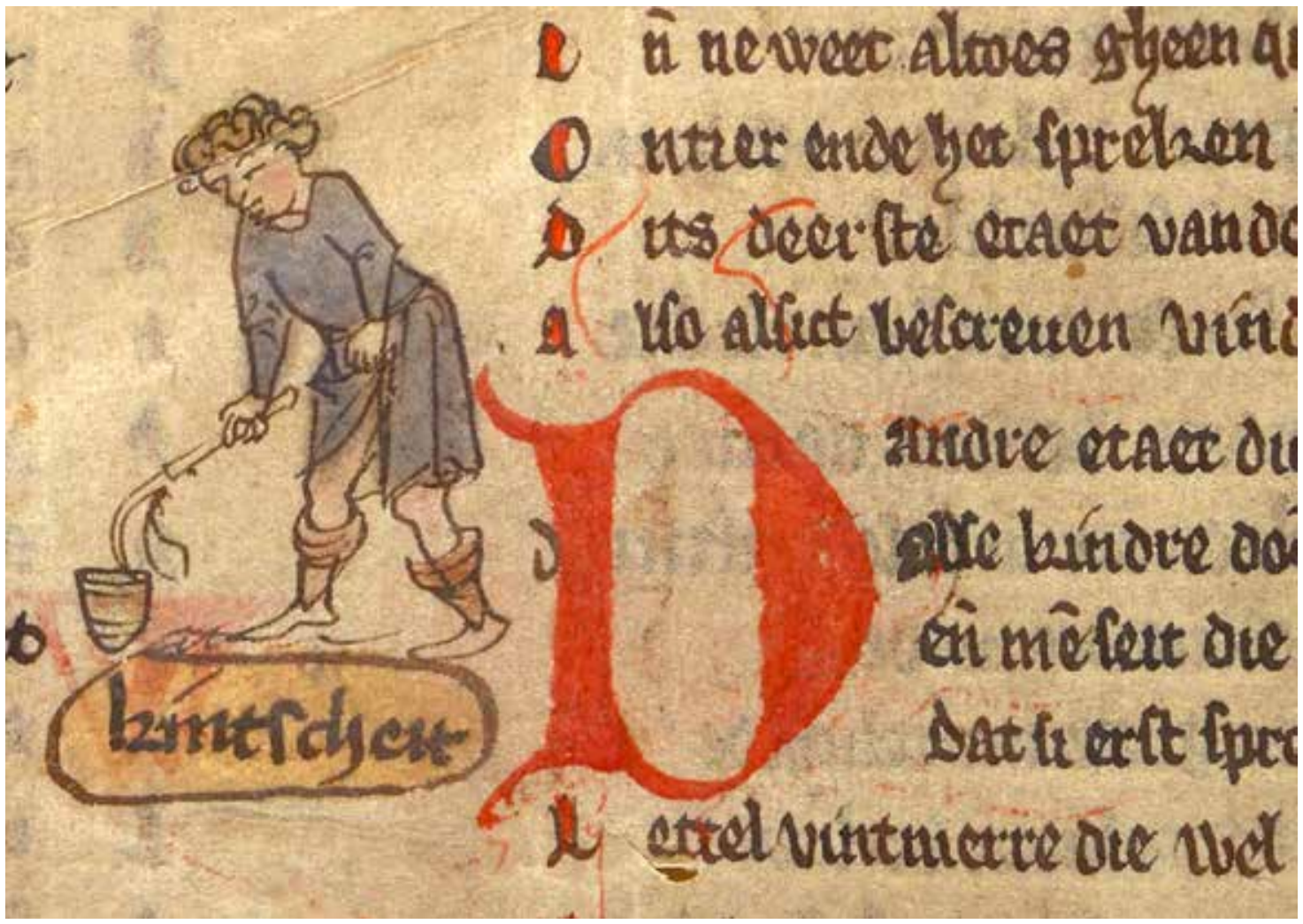

Figura 1.

Infancia: Jacob van Maerlant, niño jugando a la peonza, Der naturen bloeme, ca. 1300-1325. Londres, British Library, Add MS 11390 , f.

donde la manía del juego cede a la razón y el recato. Según el derecho canónico, este «niño» ya podía casarse - aetas apta matrimonio- o bien recibir las órdenes menores e ingresar en un monasterio ${ }^{26}$.

El mapa dibujado hasta ahora revela que no existe en toda la Edad Media una idea uniforme sobre la infancia y menos aún sobre sus juegos. Tanto es así que el concepto de «juguete» estaba aún por definir en la mayoría de lenguas vernáculas. En el Blanquerna (ca. I 283), Ramon Llull defiende a una madre llamada Aloma que no le prohibió juego alguno a su hijo ${ }^{27}$. Contemporáneo de Llull, Philippe de Novare arguye que hay que dejar jugar al niño «car nature le requiert», aunque recomienda moderación ${ }^{28}$. De hecho, la visión negativa del juego infantil no es estrictamente medieval, sino una herencia pagana, cuyos pedagogos creían que el hombre debía escapar de su stultitia inicial sin demora. Tanto es así que únicamente el puer senex o «niño viejo» es digno de alabanza ${ }^{29}$. Esta figura, más literaria que histórica, solo reviste de dignidad a los niños precoces, capaces de «razonar como ancianos» y de realizar prodigios sobrenaturales. Para san Juan Crisóstomo ${ }^{30}$ y san Agustín ${ }^{31}$, continuadores de este pensamiento latino, la infancia vulgar quedaba ensombrecida por el pecado original. En sus Confesiones, el de Hipona rememora los juegos de infancia con arrepentimiento, hasta el punto de considerarlos vehículos de perdición, como titula en uno de sus pasajes: «Pueritiae vitia quae in maiores aetates transeunt $»^{32}$.

Algunos autores cristianos osaron desmarcarse de esta tradición, negando la maldad del alma infantil y afirmando más bien el peligro de corromperla mediante los excesos del placer. Solo así se entiende que el juego infantil ocupase un lugar importante en las hagiografías y los Liber Miraculorum: «Los niños de entre dos y siete años [...], si bien apenas se representan en los miracula, son sin duda los que más juegan», afirma el historiador Didier Lett ${ }^{33}$. Es en esta edad cuando se revela la santidad del ser. En las Vita, el pequeñuelo tocado por Dios se distingue de sus camaradas justamente por su rechazo al juego o bien por la piedad que en él introduce: construye pequeñas iglesias de barro y altares con piedrecitas de río; crea misales con cortezas y escribe sermones con jugos de plantas, como hizo san Ludgero, misionero de frigios y sajones del siglo viII, según cuenta su biógrafo Altfrid ${ }^{34}$. Ciertamente, «su capacidad para rechazar los juegos mundanos hace de él un verdadero puer senex [...]. En cambio, el muchacho "normal" es aquel que se pierde jugando a cualquier $\operatorname{cosa}^{35}{ }^{35}$.

Sea por afirmación o por recusación, el juego se trueca en símbolo de la infancia. Por su con- 


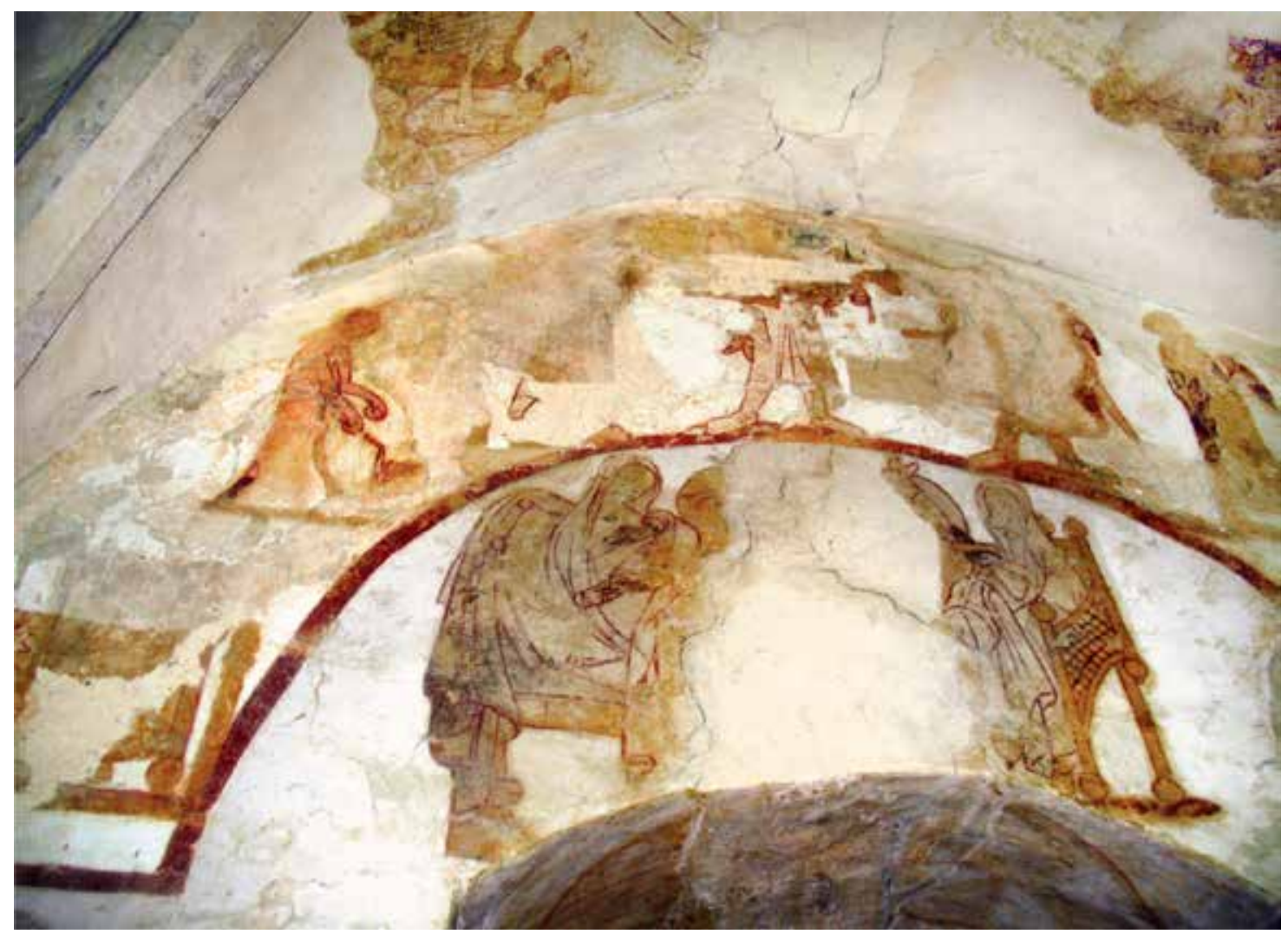

Figura 2.

Las siete edades del hombre. Mitad izquierda: cuna (infans), niño con peonza (puer), ca. 1330. Peterborough, Longthorpe Tower, sala principal del primer piso.

dición moralizante, las Vite y los Miracula no describen con demasiada precisión los juguetes procedentes de los diferentes gremios artesanales. En cambio, se habla de niños lanzando piedras, divirtiéndose en arroyos, patios y murallas con pelotas de tela, cabalgando ramas peladas, empuñando molinillos de viento a modo de lanzas y de niñas jugando con vajillas en miniatura. La literatura profana aporta algunos datos más. En la Francia del siglo XIV, el poeta y cronista Jean Froissart describe así sus juegos de infancia:

Nunca me cansaba / jugando con los demás niños [...]. / Cazando mariposas / sobresalía de entre todos ellos. / Y cuando lograba atraparlas / con una cuerdecita las ataba, / y luego las desataba / o las hacía volar como cometas vivientes. / Jugábamos a perseguirnos [...]. No pocas veces de una rama sacaba / a mi caballo Grisel [...]. / Con un cordel arreaba mi peonza / divirtiéndome día y noche. / Y con frecuencia con un junco / hacía volar una pompa de agua ${ }^{36}$.

Nos topamos con una relación similar en un poema moral escocés del siglo XV, el Ratis Raving, por cuyos versos sabemos que los niños gustaban de:
[...] Jugar con flores, construir cabañas con troncos, hacer un caballo con una rama, o una nave de vela con una hogaza partida, un trapo y un tallo para el mástil, una espada con un junco. Fabrican una bella muñeca [cumly lady] con un retal de tela decorado con flores, y la acarician con ternura ${ }^{37}$.

En el ámbito hispánico, el romancero de Luís de Góngora da buena cuenta de otros juguetes fabricados por niños: cañas para juegos ecuestres y corridas de toros en los niños, cochecitos y juegos de muñecas para «las hermanas Juana y Magdalena y las dos primillas, Marica y la tuerta», libreas de papel teñido con moras y un "peso de limas», es decir, una especie de balanza construida con dos cascos de naranja para imitar las que se empleaban para pesos pequeños en los mercados. El dramaturgo español solo menciona un juguete procedente del comercio: «un correverás que compré en la feria ${ }^{38}$ », carroza movida por el efecto de un mecanismo y de la cual, tristemente, no hemos hallado representación alguna. En efecto, los juguetes procedentes del comercio eran escasos y poco accesibles a la mayoría de las familias. Gran parte de los artefactos lúdicos ordinarios no ha dejado rastro, por haber sido fabricados 


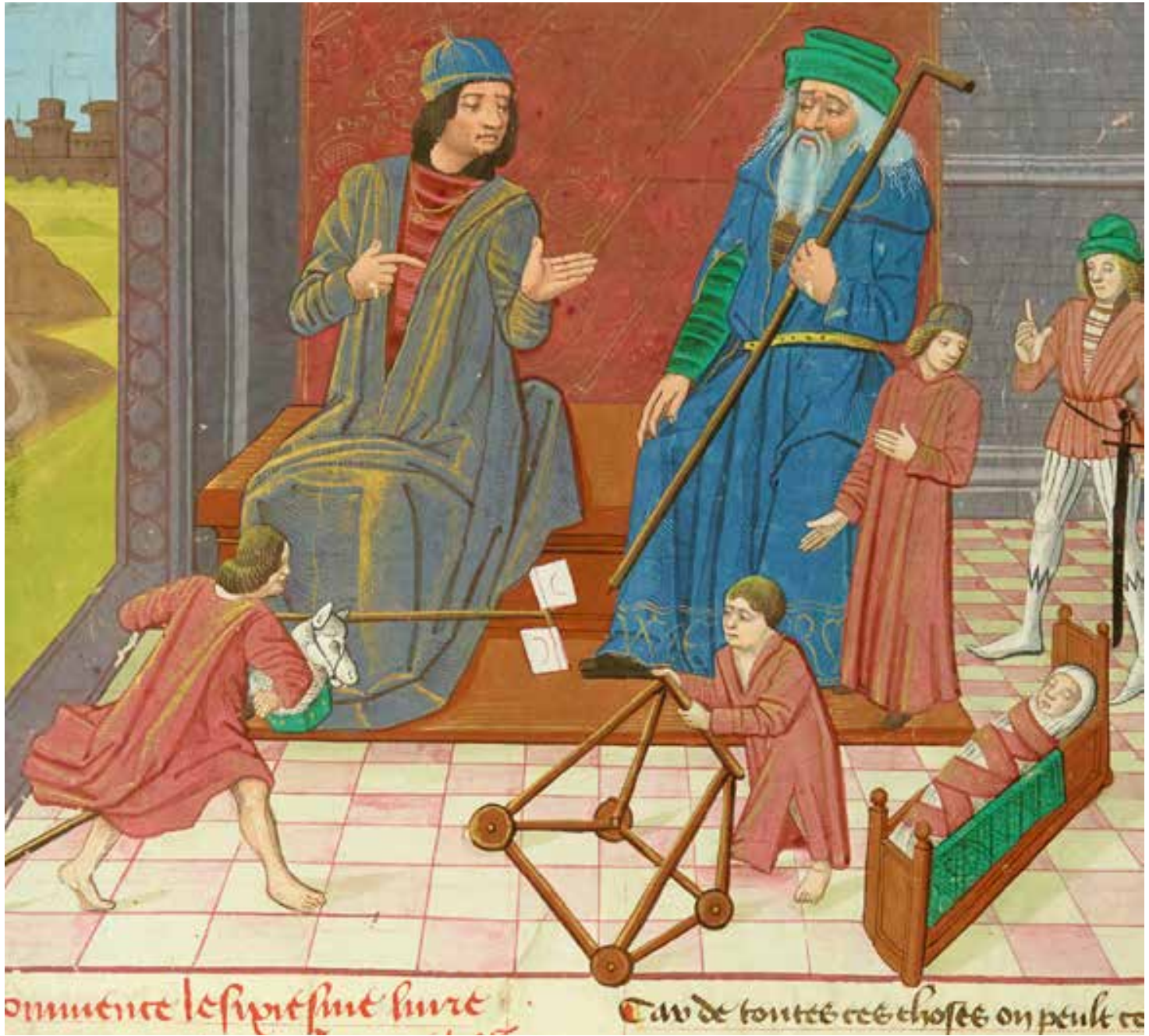

Figura 3.

Mâ̂Tre D'Yvon du Fou, Les âges de l'homme / Livre des propriétés des choses, Poitiers, 1485-1490. París, Bibliothèque nationale de France, Fr. 218, f. 95r

con materiales perecederos por los propios niños o como producto marginal de algún artesano local ${ }^{39}$. Sin embargo, vemos que tales juguetes, aunque efímeros, se convirtieron en la fuente principal de inspiración de aquellos escritores y artistas que se enfrentaron al reto de moralizar la vida humana.

\section{Primeros juguetes en el ciclo de las edades: del muro al pergamino}

Entre los siglos XII y XIV las escenas de juegos infantiles son más bien escasas y solo aparecen en los márgenes iluminados de algunos poemarios y libros de horas ${ }^{40}$. En dichas imágenes, la actividad del niño tiene más puntos en común con la iconografía de los putti de la Antigüedad que con los ciclos de las Edades. Al mismo tiempo, en las ilustraciones de dichos ciclos surgidas a partir del siglo XIV, el infans y el puer todavía aparecen despojados de todo gesto lúdico.
Concurren aisladas excepciones, como una miniatura flamenca perteneciente a una copia de la enciclopedia Der naturen bloeme - «Flor de la naturaleza» -, escrito hacia I 270 por el tratadista flamenco Jacob van Maerlant. En el margen de uno de los folios, el iluminista plasma Seis edades del hombre y la muerte simbolizando la segunda edad con un niño que hace girar una peonza con una penca (figura I).

Nuestras investigaciones revelan un caso paradigmático en la región inglesa de Cambridgeshire. Es la representación mural más antigua conocida de juegos infantiles en el ciclo de las edades. Longthorpe Tower, cerca de Peterborough, era la residencia solariega de Sir Robert Thorpe, un canciller fallecido en I 372. Las paredes de la casa estaban decoradas con varios frescos realizados hacia $\mathrm{I} 330^{41}$. En la sala principal del primer piso, las pinturas de la pared norte forman un vasto programa moralizante incluyendo las siete edades (figura 2). Después del infans en la cuna, viene el puer con una pelo- 


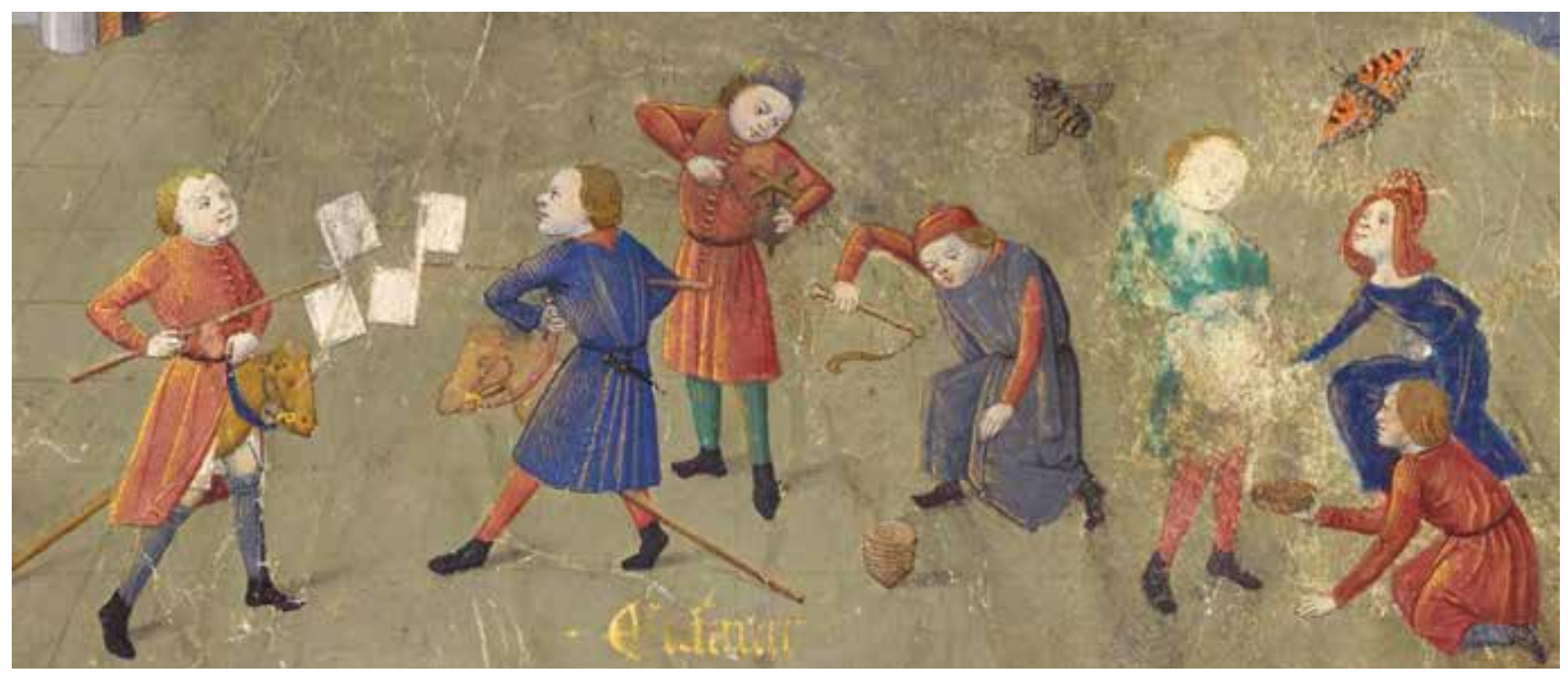

Figura 4.

Maître de l’Échevinage de Rouen (atribuido), detalle de «Enfant», en Le livre des trois âges, de Pierre Choinet, finales del siglo xv. París, Bibliothèque nationale de France, Smith-Lesouëf 70, f. 19v.

ta en una mano, mientras juega a peonza con la otra. Es importante señalar aquí que la pintura es fiel al ciclo de las siete edades descrito en $D e$ proprietatibus rerum, tratado escrito hacia I 230 por el ya citado Bartolomeo Ánglico, franciscano activo entre París y Sajonia un siglo antes de los frescos de Thorpe. Con De proprietatibus nacía una de las enciclopedias más influyentes de la Europa medieval, que dio lugar a muchas copias manuscritas y, más tarde, a incontables ediciones impresas ${ }^{42}$. En el capítulo dedicado a las edades del hombre, Bartolomeo rescata el antiguo esquema isidoriano y lo combina con el de las cuatro estaciones y el de los siete planetas de la tradición pagana. Es probable que el pintor de Longthorpe Tower se basase en esta fuente, ya conocida por aquel entonces en Inglaterra. Sin embargo, el detalle de los juguetes no pudo extraerlo de la descripción de Bartolomeo, pues no se mencionan en ninguna versión conocida anterior al siglo $\mathrm{XV}^{43}$. El detalle de los juguetes indica que podría tratarse de un añadido original del artista, convirtiendo a este fresco en la pintura mural más temprana de un juego infantil en el ciclo de las edades.

La misma figura del niño jugando a peonza aparece en los manuscritos del De proprietatibus surgidos con posterioridad al fresco de Thorpe, como si la pintura mural hubiese servido de modelo a los artistas posteriores. Lo prueba una miniatura del capítulo «De Aetate» incluida en el diccionario Omne Bonum, compuesto en Londres por el compilador inglés Jacobus entre I 360 y I 375, inspirado a su vez en el De Proprietatubus, de Bartolomeo. La capital historiada «E» corresponde a la entrada Etas, que plasma el dúo infantia/pueritia. Un andador de madera es llevado por el más pequeño mientras los dos mayores juegan a peonza y a cazar mariposas ${ }^{44}$. Seguimos en Inglaterra, veinte años después de la pintura de Longthorpe Tower.

Poco a poco, el modelo de Bartolomeo se expandió allende las fronteras inglesas a través de nuevas versiones manuscritas. Corre el año I 372 cuando Carlos VI de Francia ordena a su chambelán, Jehan Corbechon, la traducción del De proprietatibus. Dicha traducción favoreció que en el siglo XV surgiesen varias copias francesas con ricas ilustraciones, en algunas de las cuales se aprecian niños con nuevos juguetes. Valga como ejemplo la conocida versión de Maître d'Yvone du Fou, fechada hacia I485, en la que el copista introduce el andador, el caballito de palo y el molinillo de viento ${ }^{45}$ (figura 3 ). El normando Pierre Choinet, cuyos servicios como médico y astrólogo se mencionan en las cuentas del Hôtel du Roi entre I466 y I480, se basó en la traducción de Corbechon para su Livre des trois âges. Las miniaturas se atribuyen a Maître de l'Échevinage de Rouen ${ }^{46}$. En uno de los diecinueve folios que constituyen la obra, el artista borgoñón representa un aposento con chimenea, flanqueado a la derecha por una puerta de alcoba. En la estancia principal, son dos los grupos de figuras: en el plano posterior, un hombre y una mujer joven sujetan a un anciano con muletas. En el primer plano (figura 4), un grupo de siete niños parecen ajenos a la penuria de los adultos y se divierte con un conjunto de juguetes aún más rico. Reconocemos una nuez con cuatro hélices, dos bellos caballitos de palo, molinillos de dos aspas, la 


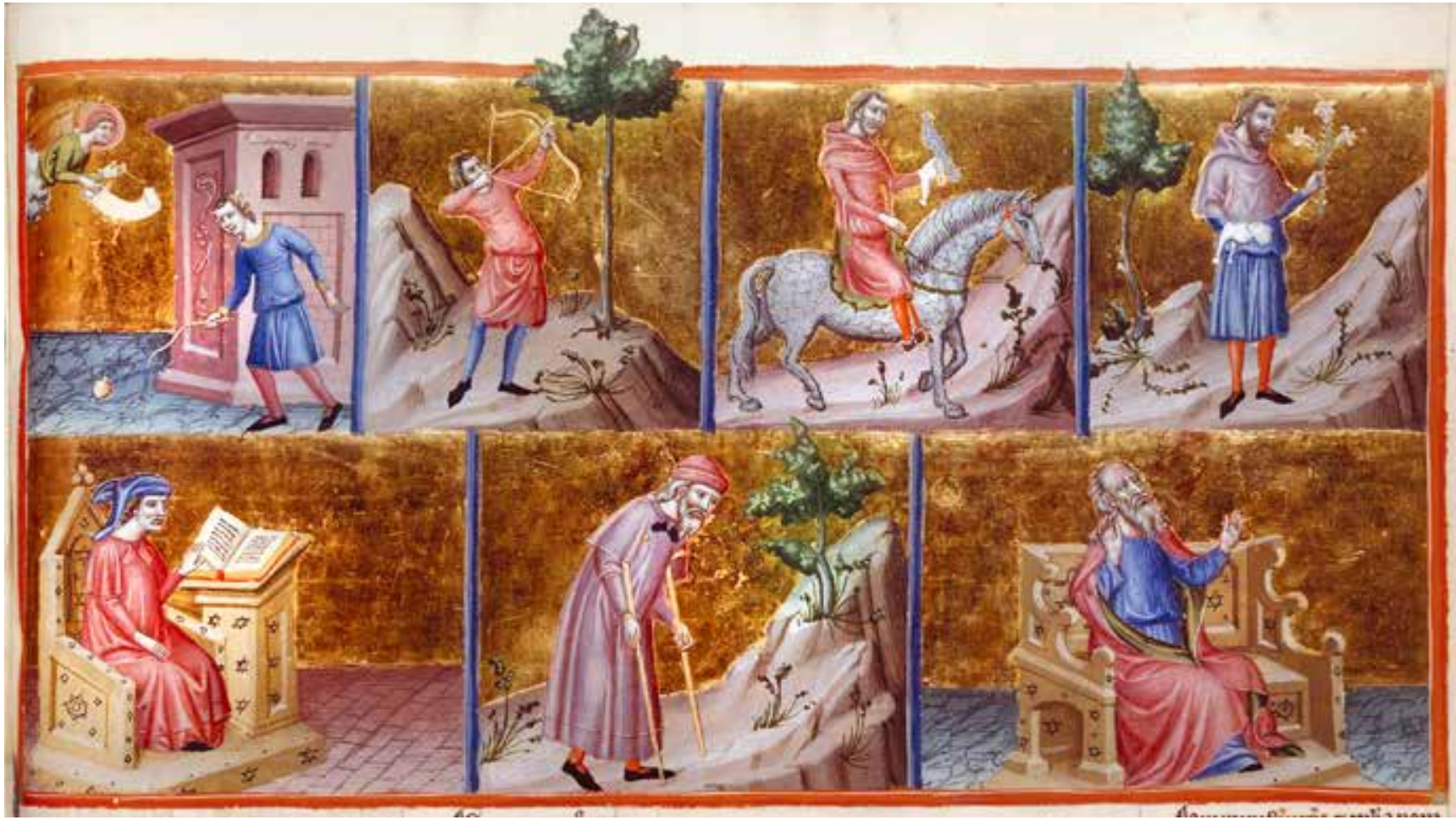

Figura 5

Anónimo catalán: Salmo 89: Las siete edades de la vida, salterio triple glosado de Canterbury, 1350-1370. París, Bibliothèque nationale de France, ms. Lat. 8846, f. 161r

peonza y la caza de insectos voladores, como en la capital historiada «E» de Jacobus.

Con todo, la enciclopedia de Bartolomé no fue la única fuente que inspiró a los pintores de finales del siglo XIV. En el contexto español, el Salmo 89 atribuido a Moisés sirvió para ilustrar las etapas de la vida y la progresión continua de los valores morales, cuyo apogeo solo se alcanza en la vejez. La Biblia de Jerusalén da a este pasaje el título de «Fragilidad del hombre». Todo el salmo es una meditación sobre la pequeñez e indigencia del hombre, hecho de barro y cubierto de pecados desde la más tierna infancia. La importancia de dicho texto queda reflejada en una ilustración realizada por un anónimo catalán entre 1350 y 1370 , incluida en un salterio glosado de Canterbury. En el folio I6I, el artista plasma siete edades, inauguradas por un muchacho, látigo en mano, atento a su peonza, que gira sobre el pavimento (figura 5). Por otro lado, una miniatura alemana de 1425 , perteneciente al De Naturis Rerum del teólogo alemán Rabano Mauro y presumiblemente inspirada en el mismo Salmo 89, presenta seis edades, en la primera de las cuales el niño agita un sonajero en su $\mathrm{zurda}^{47}$. Asimismo, varios manuscritos del norte traen consigo ruedas de la vida y de la fortuna, en las que reconocemos el andador y el caballo de juguete como atributos de la infancia $^{48}$, ilustrando así el diálogo filosófico entre la Razón y el Niño: «Niño [parvule], ¿ por qué llo- ras al entrar en las horas de la vida?», a lo que el pequeño responde: «Lloro, desnudo, por entrar en la tierra de las penas [...] pero ahora retozo tranquilo pues [todavía] libre estoy de culpa ${ }^{49}{ }$.

\section{Expansiones iconográficas en las pinturas murales de Padua, Foligno y Siena}

En la Italia de Dante, el «De Proprietatibus» de Bartolomeo fue eclipsado por otra enciclopedia: I Documenti d'Amore compuesta por Francesco da Barberino entre I309 y I3 I3, se impuso al De proprietatibus, de Bartolomeo. En el manuscrito original de Barberino se halla una iluminación con siete ruedas o esferas de la vida, ordenadas a partir de las fases del Sol. Pese al mal estado del pergamino, el infans parece montar un caballito de palo en la segunda esfera (figura Ioa). Prueba de que la escena ya estaba en circulación un siglo antes en el imaginario itálico es que Ambrogio Sansedoni glosa de este modo la fantasía del niño: «Como los niños [pueri] no pueden montar verdaderos corceles, se valen de ramas y se construyen yelmos con arcilla [galeas de $[u t o]^{50}$ ». La lógica del beato de Siena trae al recuerdo los versos de Horacio: «Aedificare casas, plostello adjungere mures, [...] equitare in arundine longa ${ }^{51}$. Afín al ciclo ptolemaico de la vida y los planetas, la visión de Barberino propi- 


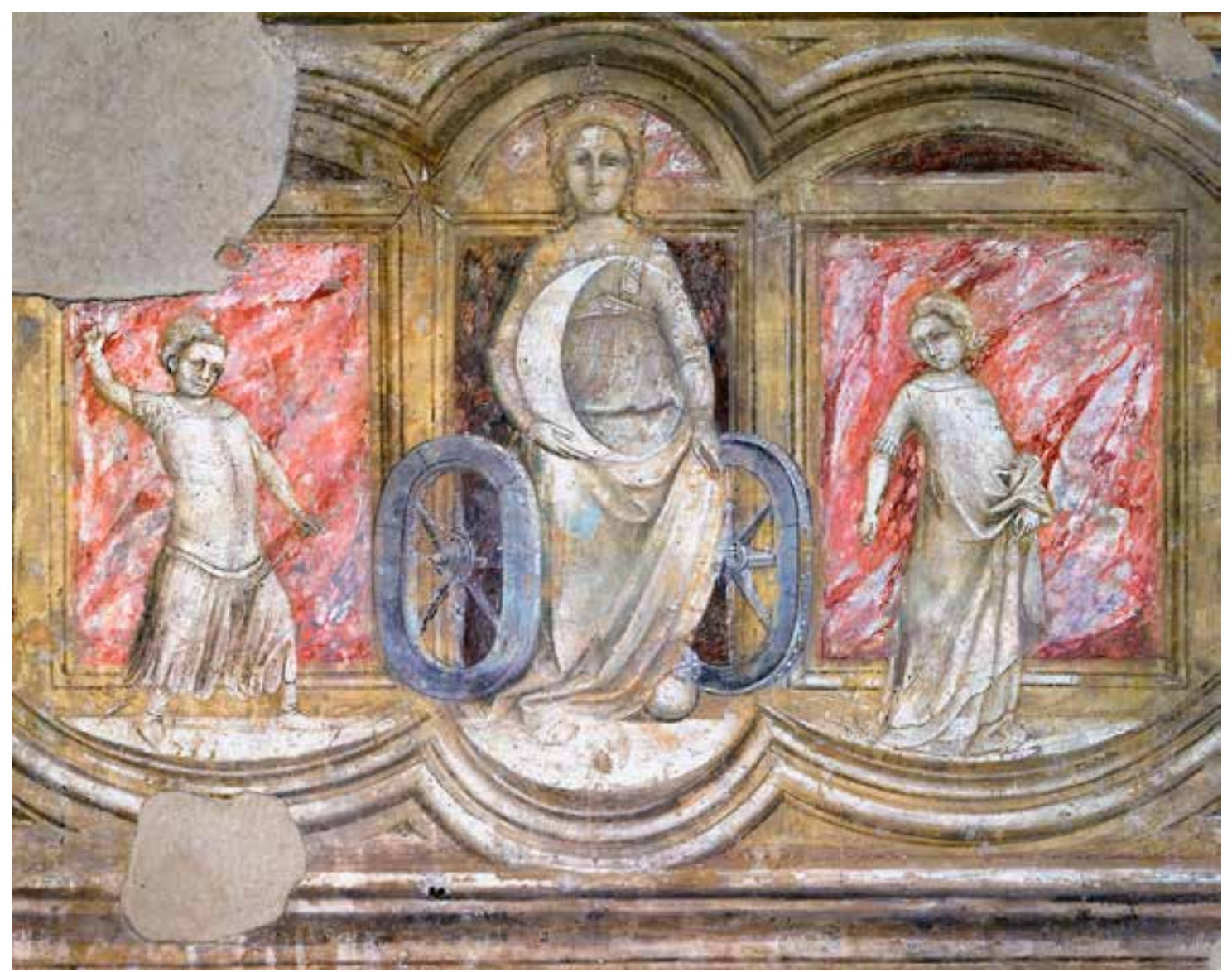

Figura 6.

Guariento di Arpo, Luna, detalle de las Siete edades de la vida, ca. 1360. Padua, Chiesa degli Eremitani, altar de san Felipe y Santiago.

ció diversas pinturas en espacios arquitectónicos que luego sirvieron de modelo, como en el caso de Inglaterra, a dos manuscritos posteriores.

Padua era conocida en el siglo XIV por albergar una gran comunidad de humanistas y astrólogos. Por aquel entonces, extensos programas iconográficos fueron promovidos en la ciudad para ilustrar la sabiduría hermética. Solo en este contexto es posible entender que el pintor Guariento di Arpo recibiese en I 360 el encargo de decorar con motivos paganos la capilla principal de la iglesia agustina de los Eremitani ${ }^{52}$. Inspirado en las siete virtudes y vicios que Giotto acababa de pintar en la vecina capilla de Arena, Guariento pintó siete edades en grisalla, imitando un fondo de mármol. Situados bajo las escenas destinadas a la vida de san Agustín, Santiago y Felipe, representó siete espacios trilobulados, todos ellos siguiendo un único esquema: un planeta personificado en el centro y flanqueado por una figura masculina y otra femenina (figura 6). Para la primera edad, el artista plasmó la Dama Luna sentada en su carro, rodeada por dos «lunáticos»: a la izquierda, un doncel con látigo equitando in arundine long a - montando un caballito de palo-; a la derecha, una mucha- cha con una muñeca en un pliegue del vestido y arrastrando un carrito con dos ruedas. Guariento no solo introdujo aquí dos juguetes nuevos, sino también una diferenciación por sexos.

Existe una iluminación de Prosdocimo de'Beldomadi inspirada en la pintura mural de Padua y fechada en I 435 (figura $7 b$ ). El copista, natural de Padua, reproduce con fidelidad la composición de Guariento, con su estructura trilobulada y las tres figuras. En el pergamino, la alegoría de la Luna aparece coronada y también sostiene el astro entre sus manos mientras su trono con ruedas se superpone a una estrella de ocho puntas. La personificación del astro presenta un rostro enfermo y su cuerpo parece postrado, quizá para representar la infirmitas de la infancia. Los juguetes son idénticos a los de la iglesia de los Eremitani. Un Liber physiognomiae de la misma época, procedente del norte de Italia y conservado en Módena, retoma el tema con más novedades (figura $7 \mathrm{a}$ ): el astro reina ahora en una carroza de cuatro ruedas. El número ocho de las puntas de la estrella invoca el signo alquímico de Cáncer, figura del zodiaco representada por el cangrejo. En la tradición hermética, Cáncer es también un signo que re- 

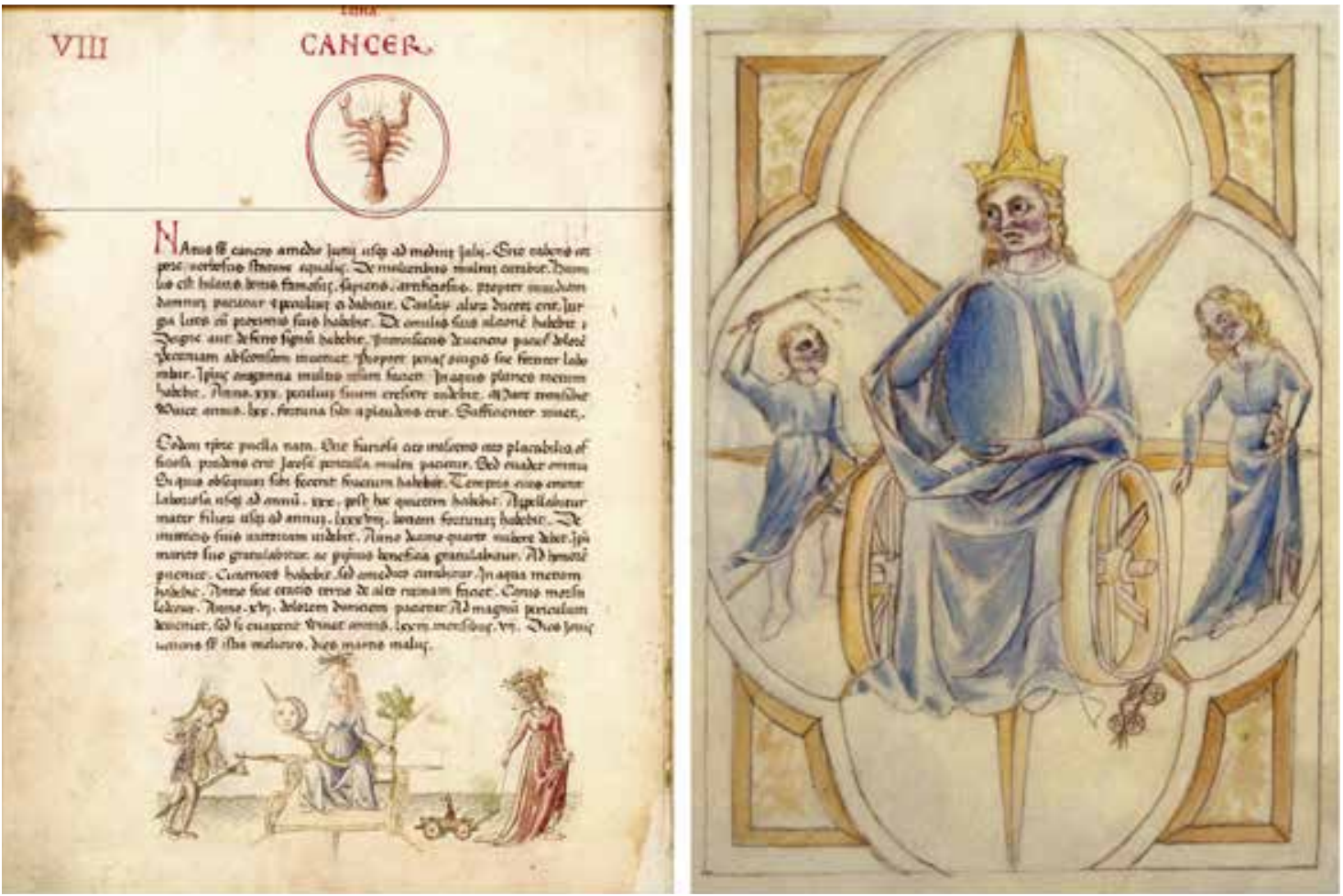

Figura 7.

a) Izquierda: Escuela de Pisanello [?], «VIII/Luna/Cancer/Infancia», la Luna entronizada bajo el signo de Cáncer, en Liber physiognomiae, ca. 1440. Módena, Biblioteca Estense Universitaria, Lat. $697=\alpha$.W.8.20, f. 4v. b) Derecha: Prosdocimus de Beldemando, Luna coronada y entronizada junto a dos niños. Oxford, Bodleian Library, MS Canon Misc. 554, f. 171r.

presenta la evolución del hombre a medida que se esfuerza por pasar del mundo físico al reino espiritual ${ }^{53}$. Por otro lado, el artista incluyó dos muñecas: la primera, oculta en el vestido de la niña como en el fresco de Guariento, y la segunda, ricamente vestida, montada en el carrito. Aquí, el juguete ya no es una simple plataforma con ruedas, sino una réplica de la carroza triunfal de la Luna. El del niño también parece más elaborado, con bridas, una escuadra a modo de cabeza y dos vástagos por orejas.

El Palazzo Trinci de Foligno, renovado durante el gobierno de Ugolino III (I405-I4I5), alberga dos ciclos distintos de frescos representando las edades del hombre. El primero de ellos y más antiguo está situado en el corredor interior o "ponte sospeso» que comunica el palacio con el transepto de la catedral. Los primeros decenios del siglo XV constituyen la edad de oro de los Trinci, cuando organizaron una corte de eruditos y humanistas, incluido Francesco da Fiano, quien inspiró varios temas pintados al fresco por Gentile da Fabriano y su taller. Sin embargo, Giovanni di Corraduccio, natural de Foligno, fue el primero en realizar en 1406 un conjunto monocromo dedicado a las Sette ettà dell'nomo y supervisado directamente por Corrado II. Si bien se trata de un boceto a base de simples líneas pardas y alguna pincelada en rosa y verde, la primera parte del conjunto todavía ${ }^{54}$ permite distinguir las siluetas de un niño y un adolescente (figura 8). El primero sostiene un látigo en la mano y mira al suelo hacia lo que debió ser una peonza. En cambio, el adolescente practica el tiro al arco, signo de madurez y virilidad.

Tras suceder a su hermano Corrado, Ugolino III impulsó la sustitución de este programa iconográfico por un ciclo polícromo de Uomini famosi, menos moralizante, al gusto del humanismo naciente. Da Fabriano y sus ayudantes pintaron sobre los frescos de Corraduccio una serie de arcos ojivales con once figuras de personajes pertenecientes a la Antigüedad judaica, grecorromana y cristiana. Entre ellos: Rómulo, Escipión, Josué, Judas Macabeo, David, Julio César, Alejandro Magno y Godofredo de Bouillon. Sin embargo, creemos que la bottega de Da Fabriano rehízo al fresco el tema de las edades en la pared derecha. Esta vez pintado con vivos colores, reconocemos al infans en la misma posición y con el mismo látigo ${ }^{55}$, mirando hacia el suelo (figura 9a). Como Guariento, tanto Corraduccio como Da Fabriano se basaron en I Documenti d'Amore, de Barberino. La disposición del nuevo ciclo de las edades, en el muro derecho, comienza con la infancia junto a la puerta de la iglesia, de forma que, al retornar 


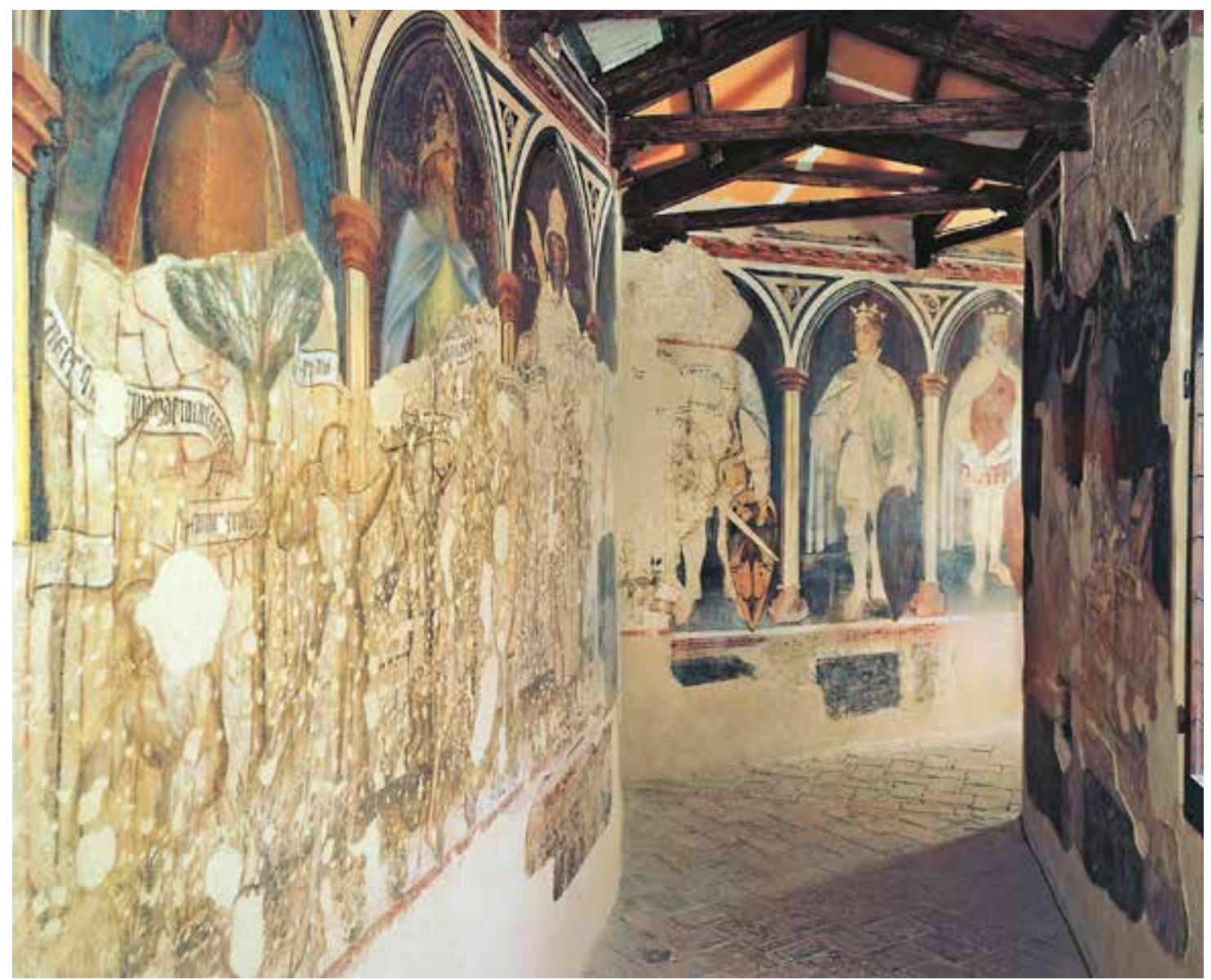

Figura 8.

Izquierda: protomuro de Giovanni di Corraduccio y muros al fresco con el ciclo de Uomini famosi, de Gentile da FabRIANO, ca. $1406-1415$. Foligno, Palazzo Trinci, corredor interior.

de la celebración litúrgica hacia el palacio, los Trinci y su corte podían meditar sobre la caducidad de la vida humana y las limitaciones de sus poderes temporales.

Tanto la versión primitiva de Giovanni di Corraduccio como la de Gentile da Fabriano incluyen un ángel que despliega sus alas sobre el infante y el adolescente. Lleva consigo dos filacterias escritas en lengua de oíl con caracteres góticos a modo de epigramas. Plantean una pregunta a cada figura. Otras dos filacterias, más cortas, dan la respuesta. La primera filacteria interroga al niño de siete años de edad: «ENFES QUE DEMANDE TU EN TENFANSE», a lo que el pequeño contesta: «SA COISANSE» («Niño, ¿qué pides en tu infancia?», «El conocimiento [= la razón]»). La segunda filacteria le inquiere de nuevo: «EN FENES QU[E D]EMANDE TU EN TÉFASE», «SANTE CROISANS... VII ANS» («Por último, ¿qué pides en tu infancia?», «Santo crecimiento... VII años» ${ }^{56}$ ).

La Camera delle Rose se abre a pocos metros del corredor. Esta sala contiene otro fresco alegórico, que fue pintado por Gentile da Fabriano entre I4I I y I $4 \mathrm{I}^{57}$ y dedicado a las artes libera- les y los planetas. En el tondo correspondiente a la Infanzia, el Sol brilla en la posición de la Aurora e ilumina a un chiquillo y su caballito de palo (figura 9, derecha). En el de la Giovinezza, la figura ofrece una corona de laurel a la Pueri$z i a$, representada por una niña que se mira en el espejo. El programa de esta cámara corresponde a un concepto didáctico extraído de la enciclopedia hermética De Nuptiis o Las nupcias de Mercurio con Filología, escrita por Marciano en el siglo $\mathrm{V}^{58}$. Los humanistas italianos de los siglos XIV y XV extrajeron de esta fuente el modelo para personificar las siete artes liberales y extrapolarlo a los siete planetas y a las siete edades del hombre descritas por Barberino:

Siete fueron los planetas imaginados y siete fueron por consiguiente las ciencias. [...] $\mathrm{La}$ vida entera del hombre se divide [...] en siete largos períodos, durante los cuales estamos sujetos al influjo de un determinado planeta y debemos volcar nuestra mente en el estudio de una disciplina concreta. Apenas nacido, el niño juguetón queda bajo el influjo de la Luna y luego pasa sucesivamente al 

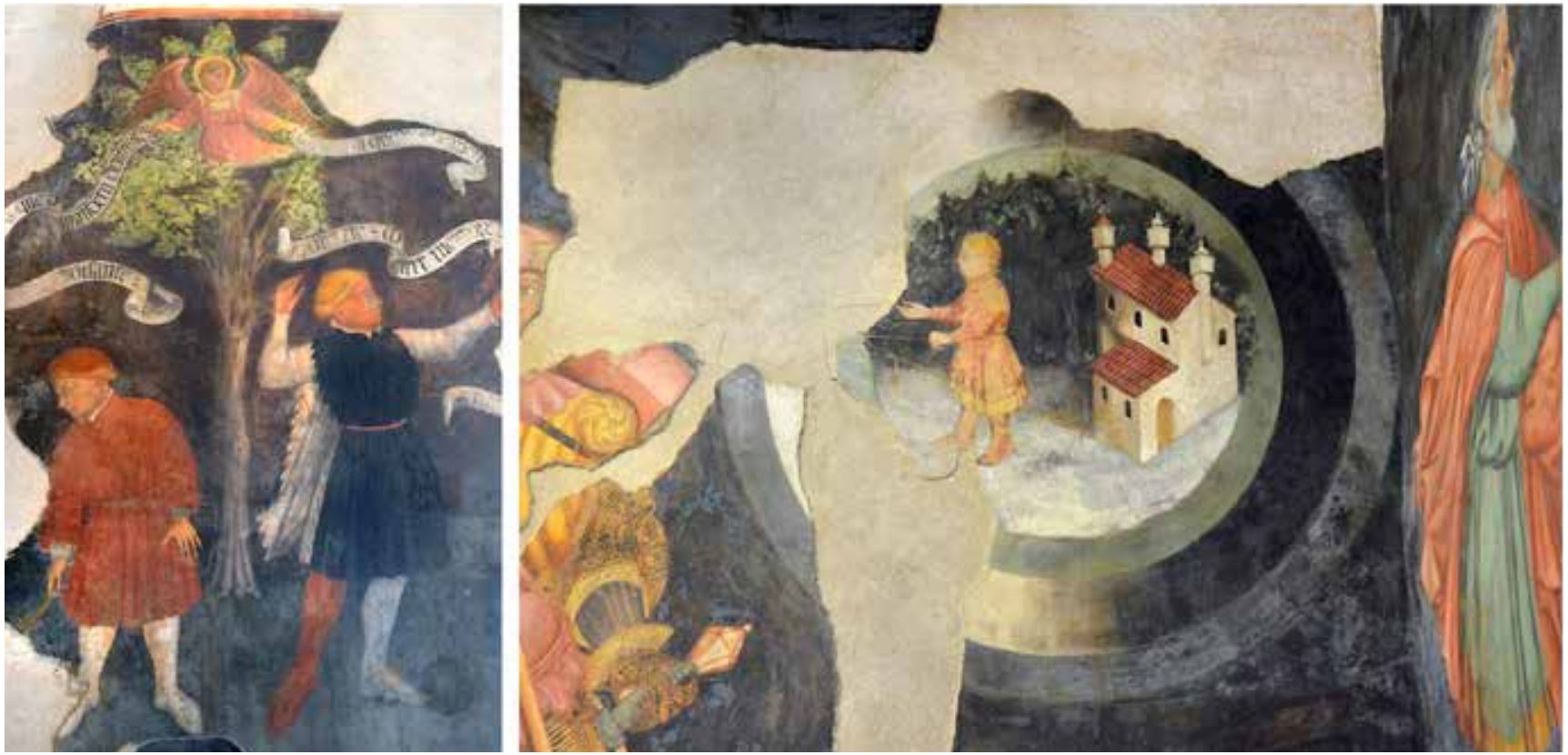

Figura 9

Izquierda: Gentile da Fabriano, infancia y adolescencia, ca. 1411, a partir de los frescos pintados en 1406 por Giovanni di Corraduccio en la pared izquierda del corredor. Derecha: Gentile da Fabriano, alegoría de la infancia, Camera delle Rose. Foligno, Palazzo Trinci.

dominio de Mercurio, de Venus, del Sol, de Marte y de Júpiter para consignarse al fin al frígido Saturno que lo sostiene hasta el día de la muerte. [...] El hombre no puede alcanzar la cumbre de la sabiduría sin pasar por todas las edades y sucumbir al poder de cada planeta ${ }^{59}$.

Así queda representada la primera edad del hombre: tutelada entrela figura de Marte, armado con lanza y espada, guantes y yelmo, armadura dorada y túnica rosácea, y la de Mercurio, pintado a modo de venerable patriarca con barba blanca. La inscripción a su pie reza: «Simile all'aurora se dimostra / Infantia sumpta per la prima Etate / Vagiendo per gran calamitate / E per miseria dela uita nostra» («Semejante a la aurora se muestra la infancia como la primera edad; deambula inconsciente entre grandes calamidades y la miseria de nuestras vidas $\left.{ }^{60} »\right)$.

Gracias a su versatilidad, el ciclo de las edades fue considerado apropiado tanto para la decoración secular como religiosa ${ }^{61}$. No solo sucede en la iglesia de los Eremitani de Padua, sino también en la catedral de Siena, famosa por su pavimento historiado. En la capilla del Voto, una parte del intarsia dispone la vida humana en seis octágonos y un rombo central. Las piezas originales fueron diseñadas por el escultor Antonio Federighi en 1475, algunas de las cuales se conservan en el Museo dell'Opera ${ }^{62}$. Aunque muchos detalles se han perdido a causa del desgaste del mármol, el contraste de las piedras blancas y negras define aún las figuras, situadas en un paisaje de flores y rocas (figura Io, centro). Infantia y Pueritia ocupan los dos primeros octágonos. De nuevo, se puede ver un caballo de palo en el primero y un aro o corona de laurel en el segundo. Según los Proverbios ${ }^{63}$, la corona del padre es el hijo y para que la rama de laurel pueda doblegarse en forma de corona, esta debe hacerlo en su primer verdor, pues al crecer se endurece y se quebraría. De ahí la Voz divina: «Filii tibi sunt? Erudi illoset curva a pueritia cervicem illorum» ${ }^{64}$.

El códice Documenti d'Amore, de Barberino, conservado en el Vaticano, presenta una analogía no desdeñable entre la estructura de las siete ruedas y la composición en octágonos de Federighi. La posición del Infans con las rodillas dobladas y la espalda arqueada para cabalgar sobre la rama es también muy similar (figura Io). En ambos casos, es posible que el niño sostenga además en su mano derecha una fusta para arrear al juguete. Sin embargo, la de Barberino no fue la única obra que establecía dicha relación. El capítulo «De horis et aetatibus» de la Gemma animae, compuesta por Honorio de Autun en el siglo XII, había parangonado la infantia a la aurora, la pueritia a la primera hora y la adolescentia a la hora tercera ${ }^{65}$, aunque ignoramos si Federighi conoció la obra del cosmólogo alemán. Entre otras influencias literarias de Federighi que sí podemos acreditar, cabe mencionar, junto al ya citado Ambrogio Sansedoni, el soneto de las Etates, de Simone 

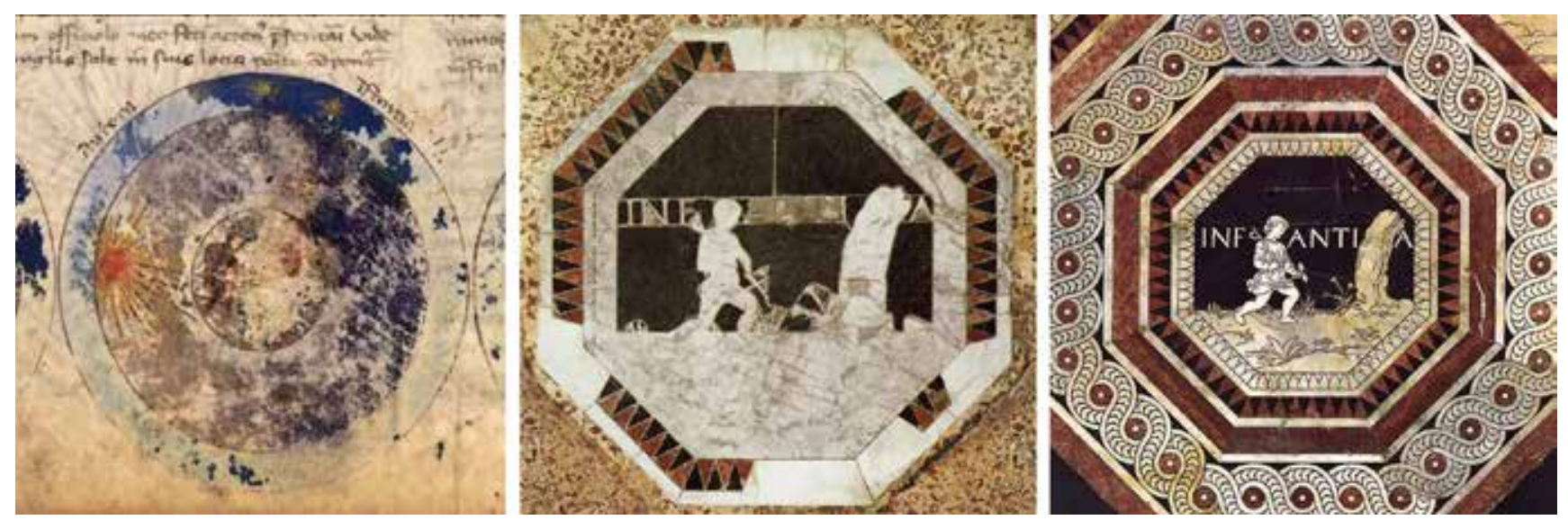

Figura 10

Izquierda: Maestro del Códice de SAn Jorge, rueda de la infancia, detalle de Documenti d'Amore, Francesco da Barberino, 1309-1313. Ciudad del Vaticano, Biblioteca Apostólica Vaticana, Barb. Lat. 4076, f. 76v.-76r. Centro: Antonio Federighi, Infantia, 1475-1476, pavimento original del Duomo. Siena, Museo dell'Opera. Derecha: L. MAcCARI y G. Radicchi, restauración a partir de un cartón de Alessandro Franchi reinterpretando Infantia en el ciclo de las Siete edades del hombre, de Federighi, 1871. Siena, pavimento del Duomo.

de’Prodenzani (ca. I4 I 5). Los siguientes versos inauguran su Liber Saporecti refiriéndose a los juegos infantiles: «Doppo tre anni comencia a cavalcare / sopra la canna e questo è'l suo ronzino, / non avendo pensier de nullo afare ${ }^{66}$ ». En la misma Siena, las Prediche, de Bernardino (ca. I427), describirán una escena idéntica: «Vedeste mai e fanciullini quando fanno e balestrucci, e vanno a cavallo in su e cavagli de la canna co la spada di canna ${ }^{67}{ }^{67}$. Valga añadir que la reconstrucción del pavimento realizada en I87 I ofrece una variación: el infans monta un molinillo de juguete a modo de caballo y no una simple rama (figura ıo, derecha). Este detalle es único en la iconografía medieval, por lo que resulta difícil saber si fue una licencia de los restauradores o bien una innovación original de Federighi.

El caballito de juguete reaparece en otros lugares del pavimento del Duomo, aunque fuera del ciclo de las edades. El pintor Matteo di Giovanni, diez años más joven que Federighi, recibió el encargo de plasmar la masacre de los inocentes. El maestro operario Alberto Aringhieri colaboró con él para traducir a mármol el drama narrado por san $\mathrm{Mateo}^{68}$. La historia se corona con un friso repleto de faunos y Erotes infantiles, algunos de ellos alados, que comentan la matanza decretada por Herodes. Esta última parte fue realizada entre I48 I y I482 por los discípulos de Di Giovanni, Francesco di Niccolaio y Nanni di Piero. Uno de los putti sostiene, en efecto, un palo acabado en forma de cabeza triangular, rematada por dos plumas u orejas ${ }^{69}$, recordando la forma de un animal para montar; por más que también pueda tratarse de un molinillo de viento de factura imprecisa. Por último, el molinillo es representado por tres veces y con toda claridad en el pavimento que Domenico Beccafumi diseñó entre i 5 I 9 y I 52 I dedicado al ciclo de Elías y Acab y la Historia de Moisés ${ }^{70}$.

\section{Vientos de humanismo: la multiplicación de los soportes y de los juguetes}

La Italia de finales del Quattrocento y principios del Cinquecento trae consigo nuevos soportes iconográficos relacionados con el ciclo de las edades y los juegos infantiles, como los deschi da parto o «bandejas de nacimiento». Estos objetos en tondo eran encargos de las familias acomodadas de Siena y Florencia con motivo del alumbramiento del primogénito. Solían estar pintados por artistas de renombre, tales como Bartolomeo di Frusino, Lorenzo di Niccolo, Lo Scheggia - hermano de Masaccio-, Giovanni di Paolo y Pontormo. Los artesanos, banqueros y comerciantes que adquirían una notoriedad política y financiera gustaban de regalar dichas bandejas. En ellas solían representar motivos heráldicos, sucesos mitológicos y escenas infantiles: a menudo juegos de competición y con animales de compañía, así como chiquillos desnudos empuñando sus primeros juguetes. Los más antiguos se fabricaban en madera; luego en mayólica por evidentes razones de higiene. El desco se cubría con paños para servir de recipiente durante el parto. Más tarde se colgaba en la pared como recuerdo de tan insigne día ${ }^{71}$. Desde el punto de vista compositivo, los pintores toscanos se basaron en la iconografía de las edades para plasmar la figura del primogenitum.

Un disco florentino de 1420 representa, en uno de sus lados, el «jardín del amor» habitado 


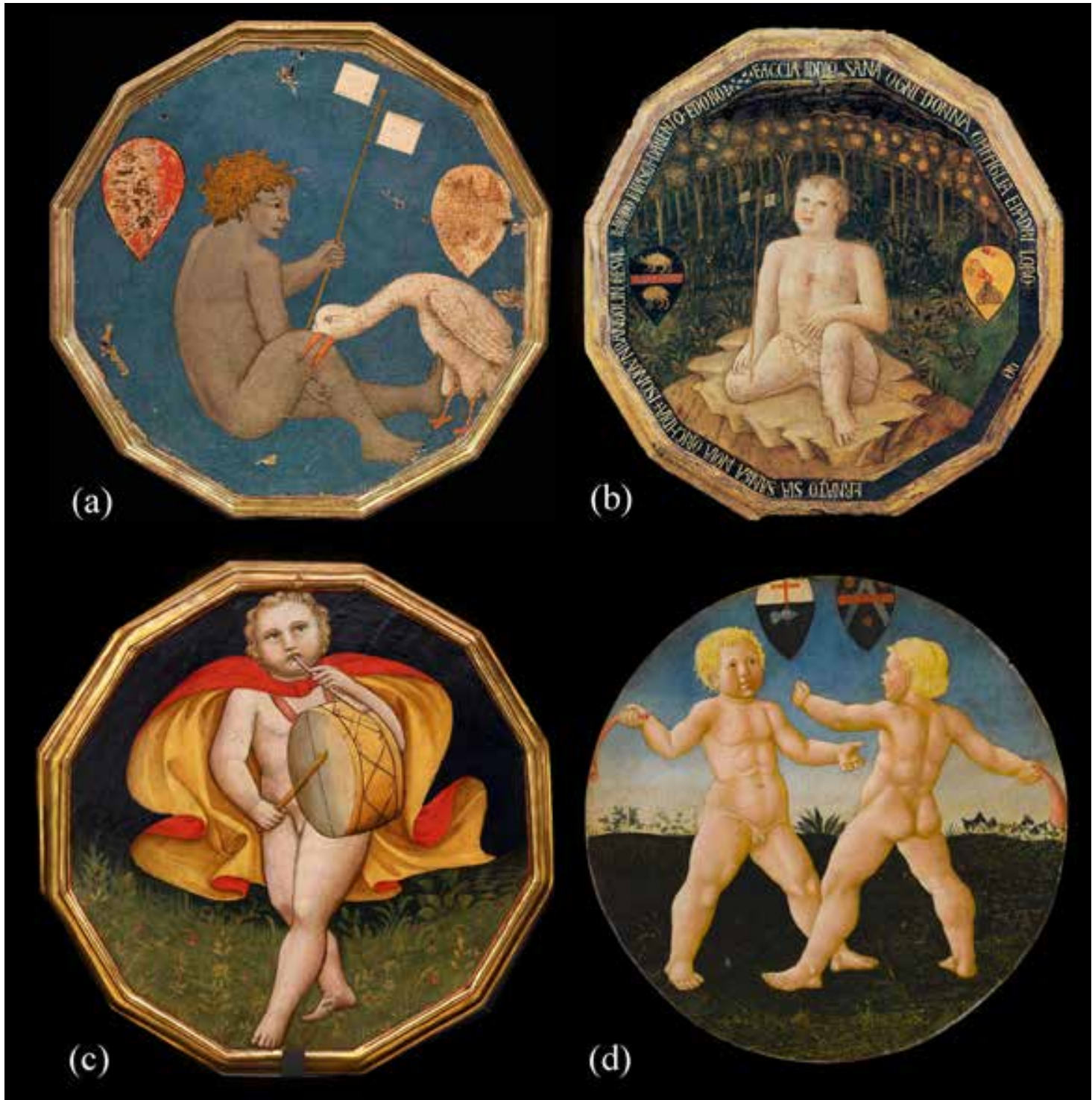

Figura 11.

Discos de parto, témpera en tabla. a) Escuela florentina, anverso: Jardín del amor; verso: Niño jugando con una cigüeña, ca. $1420, \varnothing 51 \mathrm{~cm}$ Nueva York, Grassi Collection. b) Bartolomeo DI FRUOSINO, anverso: Nacimiento de san Juan Bautista; verso: Niño con molinillo $y$ caballito de palo en el bosque, 1428, Ø $59 \mathrm{~cm}$. Isola Bella, Museo Borromeo, New York Historical Society. c) Lippo D'ANDrEa (Pseudo AmbroGIO DI BALDESE), anverso: Justicia de Trajano; verso: Niño tocando el tambor y la flauta entre flores, primer cuarto del siglo xv, $\varnothing 71 \mathrm{~cm}$. Londres, Trinity Fine Art Collection. $d$ ) Lo Scheggia (= Giovanni di Ser Giovanni Guidi), Niños jugando al civettino, segunda mitad del siglo xv, Ø 63,5 cm. Londres, Moretti Collection.

por jóvenes en danza bajo un naranjo y una higuera y músicos que tocan junto a una fuente de la vida repleta de peces. En el otro lado, hallamos un niño desnudo, pelirrojo, en compañía de una cigüeña y un molinillo de dos aspas, rodeado de dos escudos cuya heráldica es hoy irreconocible (figura I Ia). Mientras la imagen del juguete actúa como un símbolo claro del impulso lúdico en esa edad, la cigüeña es un símbolo de buen augurio. En el siglo XV ya existía la creencia de que su sola mirada podía causar la concepción y también era celebrada como portadora de los recién nacidos. Al tratarse de un ave migratoria, su regreso a las campiñas europeas corresponde al despertar de la naturaleza tras el duro invier- no. Una primavera que se asocia también a la primera edad del hombre ${ }^{72}$.

Un desco pintado en $\mathrm{I}_{42} 2$ por el florentino Bartolomeo di Fruosino muestra a un niño sentado sobre una roca en medio del bosque (figura i ib). Lleva un amuleto atado al cuello. Se trata de un fragmento de coral, cuyo poder, ya conocido en la antigua Roma, protegía al recién nacido de la muerte y las enfermedades. Pero también servía como tintinabula si se engarzaba con campanillas y pequeños sonajeros ${ }^{73}$. En la mano derecha lleva un molinillo de juguete y bajo la pierna izquierda guarda un caballito de palo muy parecido al que pintó Guariento en Padua. Por su parte, Lippo de Andrea, miembro de la Com- 


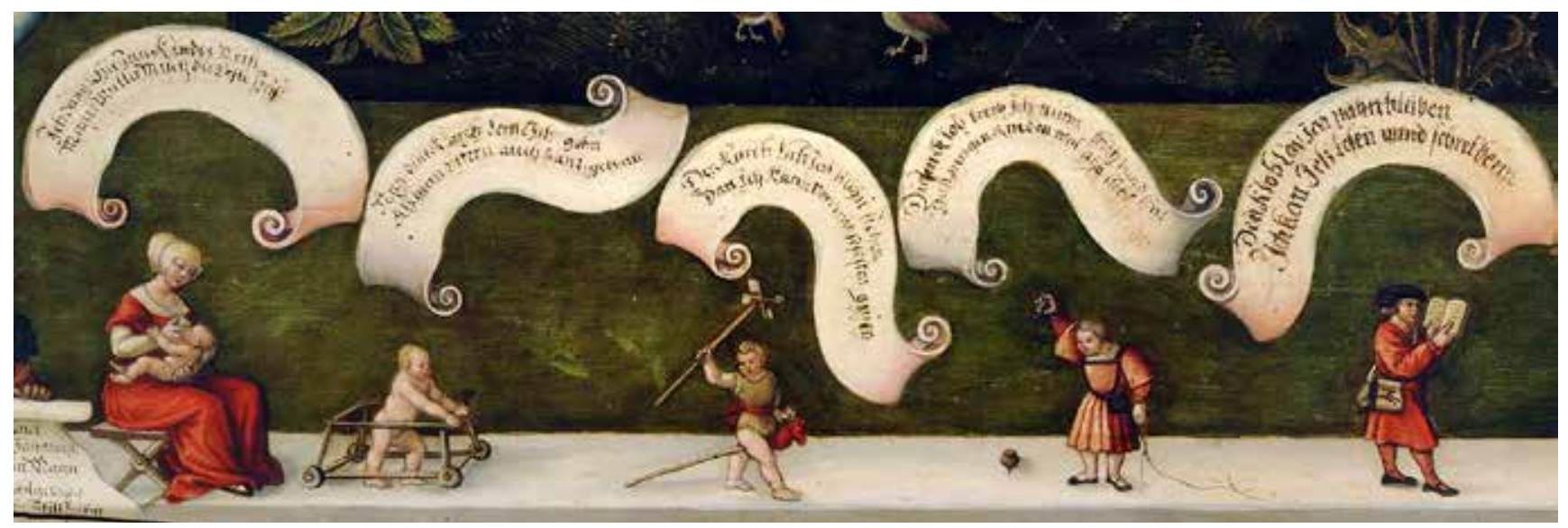

Figura 12 .

Fragmento de Las edades de un caballero, mesa plegable, Alemania, 1528. Estrasburgo, Musée de l'Euvre de Notre-Dame, 22.2010.1.1.

pañía de San Lucas, plasma un putto con túnica roja al vuelo y caminando sobre un manto de flores (figura I Ic). El pequeñuelo toca el tambor colgado del cuello al tiempo que sopla una flauta primitiva. En cambio, Lo Scheggia prefirió pintar una escena con dos pueri batiéndose en furibundo combate. Se trata del juego del $\mathrm{C} i$ vettino $^{74}$ : los jugadores debían pisar el pie del adversario para inmovilizarlo e intercambiar golpes con las manos. En este caso, el artista entrega un curioso objeto a cada niño, a modo de manguito elástico, hecho tal vez de vejiga de cerdo o de carnero.

La iconografía de los deschi da parto inspiró, décadas más tarde, pinturas como Aetas Pverilis, atribuida a Jacopo Chimenti, perteneciente a un ciclo mural de las edades y las estaciones destinado a una casa palaciega de Empoli ${ }^{75}$. Los ejemplos analizados hasta aquí revelan una lenta pero imparable especialización de los juguetes en función de las edades de la infancia, también por sexos. Una realidad impensable dos siglos atrás. Como en el caso de Jacopo Chimenti, aparecerán nuevos ciclos de las edades en pinturas arquitectónicas representando juegos infantiles, especialmente en el norte. Entre las pocas que han sobrevivido hasta nuestros días, cabe citar los frescos del castillo austríaco de Rappottenstein y la Head Master's Chamber de Eton, en el condado inglés de Berkshire.

En el siglo XVI, los juguetes abandonan definitivamente la frialdad de los muros y la privacidad de los manuscritos para conquistar nuevas artes muebles. Prueba de ello es, por ejemplo, su aparición en los tapices manufacturados en Flandes, Francia e Inglaterra. Tomás Moro se topó en I 5 I 4 con uno de estos tapices, reconociendo en la primera de sus escenas - que titula «Chyldhod» - la presencia de un niño fustigando la peonza, como en el manuscrito catalán de
París y el Infans pintado por Corraduccio en el palacio de los Trinci. El santo describió la imagen en un poema mediante la voz de un pícaro cuyo único propósito es pasar la vida jugando:

Infancia me llamo; toda mi mente el juego [invade, Lanzo aros, bolos y con brío ruedo la pelota. La peonza es mi diversión, pues al girar me [evade.

Ojala toda la odiosa lectura que me embota $\mathrm{Al}$ fuego yo arrojase con un golpe de mi

[bota.

Mi vida entonces gozaría en eterno juego: Esa de Dios, a la que hasta el día final me

entrego $^{76}$.

La reciente restauración de una mesa plegable de I 528 , propiedad de la familia del autor satírico Sébastien Brant, conserva un panel de excelente factura pictórica con veinte escenas de la vida de un caballero célibe. El artista, desconocido, dividió la infancia en cuatro edades atribuyendo a cada una los principales juguetes de los que hemos hablado (figura I 2). Tras el destete, el andador simboliza la necesaria corrección de la torpeza de los primeros pasos del hombre. El despertar de la imaginación es representado por el caballito de palo y el molinillo. Luego viene la peonza, juego que exige de una habilidad más propia de una infancia avanzada. En la fase final, el niño cambia sus juguetes por el libro, que sostiene abierto entre sus manos. Ha llegado a la edad del estudio, donde la razón se impone sobre los impulsos lúdicos. Esta última figura recuerda la futura admonición de Lord Chesterfield hecha a su hijo en la víspera de su noveno cumpleaños: "iNo más ligereza! Los juguetes y cachivaches infantiles deben ser desechados y tu mente debe posarse para bien 


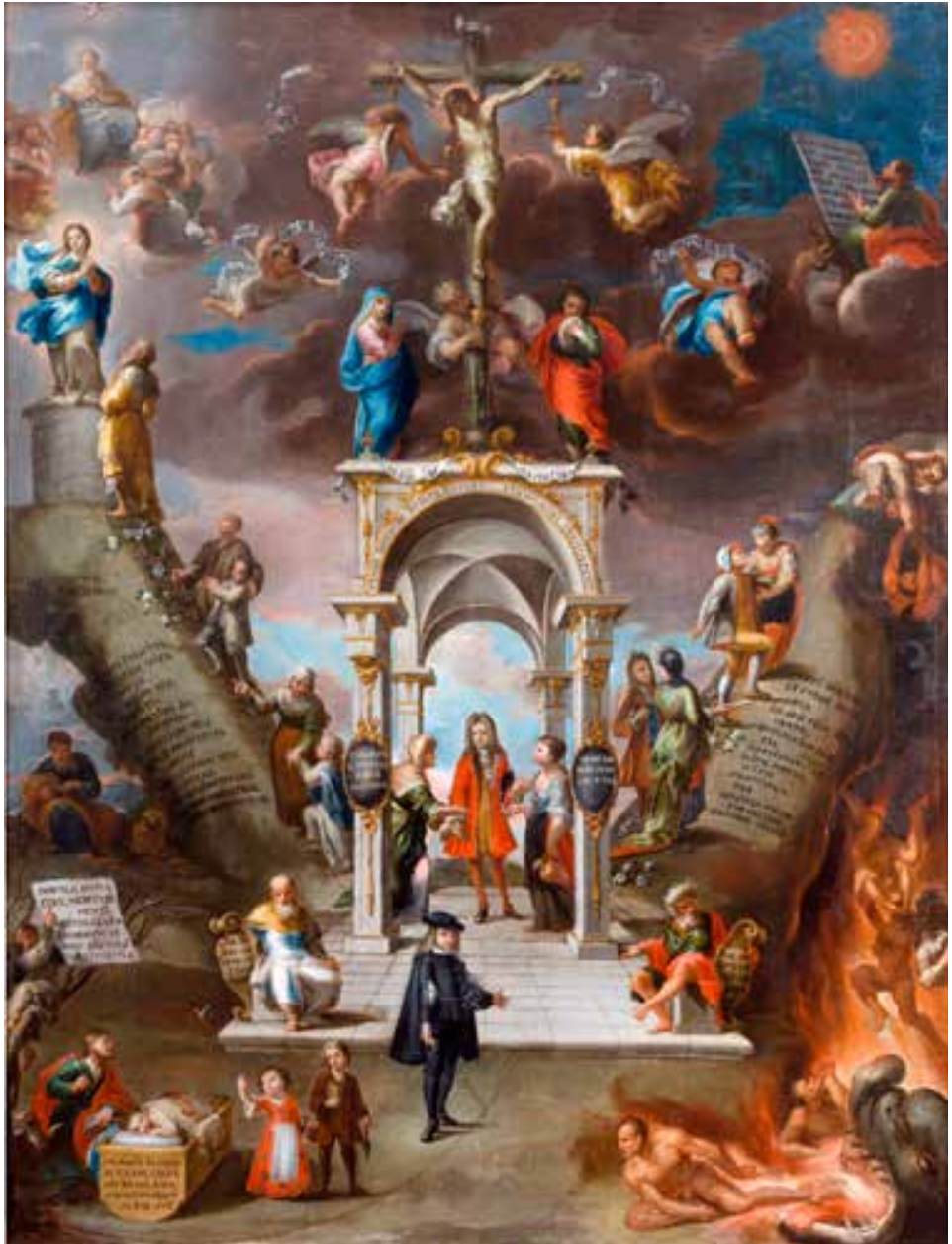

Figura 13.

Escuela castellana, Alegoría de los caminos de la salvación y de la perdición, siglo xvir. Óleo sobre lienzo, 170 x $132 \mathrm{~cm}$. Salamanca, Monasterio Madres Franciscas Descalzas.

sobre los objetos serios ${ }^{77}$ ». Otros muebles de uso doméstico de misma época alargan la edad de los juegos, como la vasija con diez edades de la vida de origen alemán conservada en el Museo de Cluny. En ella, un niño de diez años — «io. Iar.Ein.Kind» - cabalga un magnífico caballito de juguete en medio de una verdura floreada.

La proliferación de las Ætates hominum en los siglos del humanismo renaciente propició la primera clasificación de los juegos infantiles, dotándolos de un simbolismo específico y revelando un reconocimiento paulatino por parte de la cultura adulta. De lo contrario, no podríamos entender la aparición de pinturas como Die drei Lebensalter und der Tod, de Hans Baldung Grien ( I 509-I 5 I0), y Die Kinderspiele, de Pieter Bruegel ( 560 ), ambas conservadas en el Kunsthistorisches Museum de Viena. Especialmente la de Baldung constituye un documento sincrético de primer orden. Representa únicamente las edades de la mujer. La Muerte, bajo la apariencia de un cadáver, blande un reloj de arena junto a la joven dama que contempla su radiante desnudez en el espejo - como en la Sala delle Arti liberali e dei Pianeti de Foligno-. El pintor envuelve su alegoría contra la lujuria y el orgullo en un entorno boscoso con tintes primaverales. Baldung nos recuerda que la belleza carnal es transitoria, pero también podría entenderse su pintura como un triunfo de Venus y del amor sobre la muerte. A este guiño se le superpone la iconografía de las edades. A los pies de la bella dama, una niña recién nacida juguetea con el velo traslúcido que se cierne sobre su cabeza. La niña representa la infancia que la joven ha perdido, yuxtapuesta al cuerpo exangüe de la anciana en la que se convertirá. Esta última intenta mover el espejo de la doncella para que en él se refleje el rostro de la muerte. Mas no debemos pasar por alto que a los pies de la niña yace, como abandonado entre la hierba, un hermoso caballito de palo, semejante a los que procedían del comercio local. Para representarlo con tanto detalle, el pintor tuvo que observar bien los juguetes infantiles de Núremberg, la ciudad en la cual vivía por aquel entonces. El hecho no es baladí, pues Núremberg fue la «capital» europea del juguete artesanal en los siglos XV y XVI. Realismo, alegoría y fantasía coexisten en esta obra que asocia la infancia a un único objeto simbólico, cuya elección por parte del autor no tiene por qué ser anodina. Allende la explicación sociológica que hace del caballo un animal fundamental en el desarrollo práctico de la vida, el esoterismo del cuadro nos lleva a preguntarnos la razón por la cual Baldung habría introducido este juguete tradicionalmente asociado a la infancia masculina en un ciclo representativo de la mujer. ¿Acaso el recién nacido podría ser también el hijo de la joven dama, recogiendo así la idea de una infancia universal? ¿Podría ser el caballito de palo símbolo del tiempo que galopa para todos? El símil no es improbable, pues un grabado publicado en Estrasburgo en I 535 para ilustrar la obra Schimpff und Ernst, del predicador franciscano Johannes Pauli, nos muestra una personificación de la muerte cabalgando un caballito de juguete ${ }^{78}$. No olvidemos que Hans Baldung Grien vivía en Estrasburgo cuando esta ilustración fue estampada y publicada en dicha ciudad.

La proliferación de la imprenta no hizo sino acelerar el reconocimiento de la infancia y el valor simbólico de sus juegos. La xilografía tomó el relevo de las miniaturas iluminadas, seguida a su vez de los procedimientos calcográficos a partir del siglo XVI. Estos últimos agilizaron la estampación en serie, lo que abarató el coste de las imágenes. La iconografía de las edades encontró así nuevos clientes y nuevas propuestas artísticas.

En este sentido, merece una mención especial la iconografía de los «caminos de la salvación y de la perdición» en el ámbito hispánico. En plena Reforma católica, la estructura de las edades 


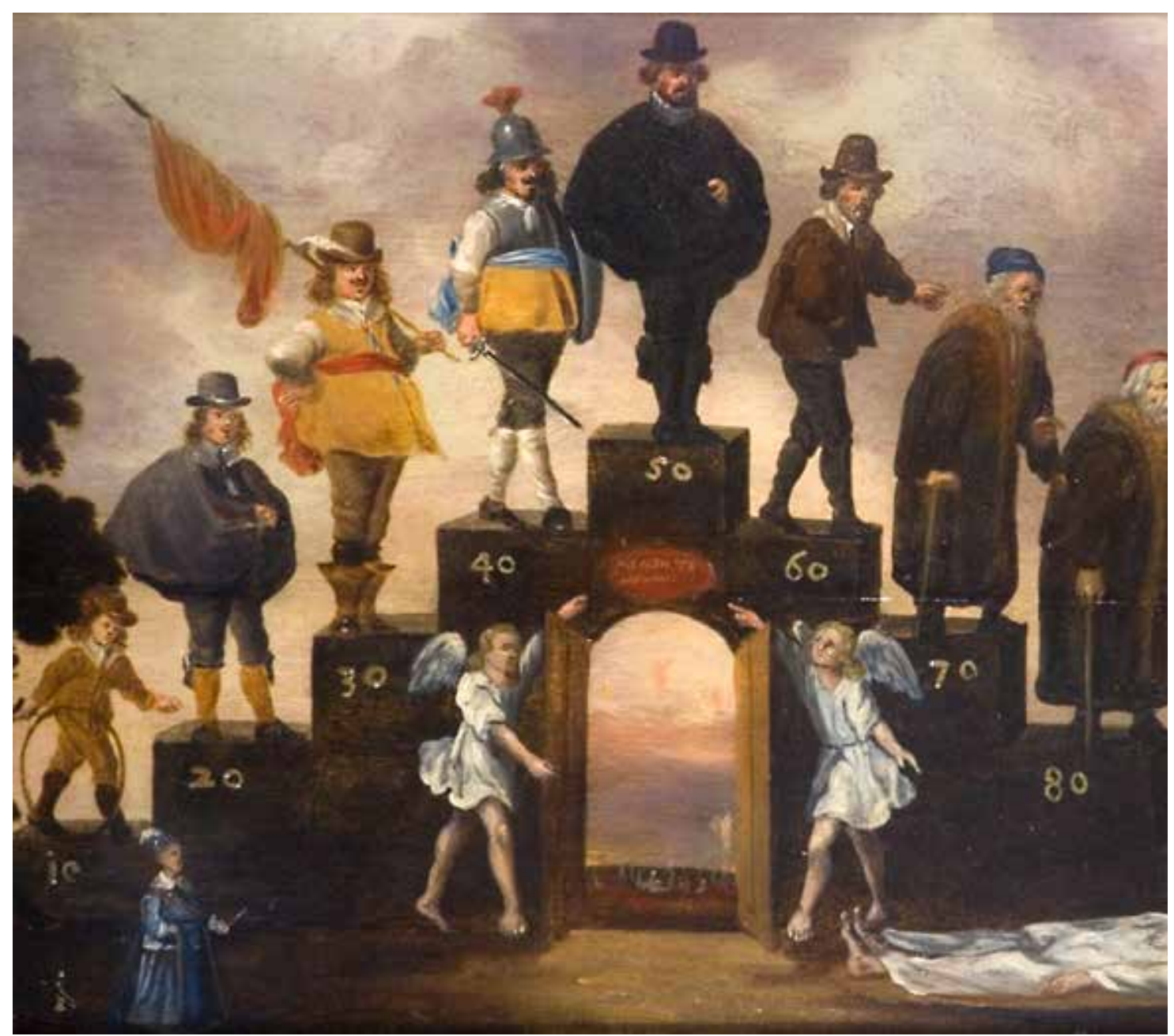

Figura 14.

Cornelius Saftleven, Las edades del hombre, Rótterdam, ca. 1630. Óleo sobre tabla, 44,5 x 58,4 cm. Birmingham, University of Birmingham Collection, BIRRC-A0266.

se mezcla con el itinerario de la vida cristiana, tal como lo describirá san Juan de la Cruz. El propio santo esquematizó dicho camino en un conjunto de dibujos autógrafos realizados hacia I 578 y conocidos como Monte de perfección. Se conserva copia notarial de uno de ellos: el dirigido a la carmelita descalza Magdalena del Espíritu Santo ${ }^{79}$. Aunque en él no hay representación humana alguna, la estructura recuerda a una xilografía de i 546, publicada en el tratado moral Pentaplon Christianae pietatis, compuesto por el teólogo y gramático Antonio de Honcala ${ }^{80}$. La obra se publicó en Alcalá de Henares durante los primeros años del Concilio de Trento y estaba dedicado a la educación del joven Felipe II. La alegoría fue diseñada y estampada por el impresor Juan de Brocar. Forma una gran letra ípsilon para mostrar la disyuntiva entre el vicio y la virtud a la que se enfrentaría el príncipe a lo largo de su vida. Según Geoffrey Parker ${ }^{81}$, el niño que va creciendo es el propio monarca, con sus juegos y quehaceres. Tras la edad de la cuna, el infante juega con un molinillo de viento y con un pajarillo atado a una cuerda a modo de cometa viviente. Si bien el primer artefacto ya es conocido, el segundo es un juguete inédito en el programa de las edades.

Dicho modelo dio origen a pinturas de gran formato, como el óleo sobre lienzo titulado Alegoría de los caminos de la salvación y de la perdición, obra de piedad de mediados del siglo XVII (figura I3). Resulta evidente que el autor se basó en el grabado del Pentaplon Christianae pietatis. La obra estaba destinada al monasterio de Clarisas Franciscas Descalzas de Salamanca, fundado en i6o r bajo la advocación de la Purísima Concepción, figura que corona, junto con la de Cristo, la cúspide del camino. La inscripción en el frontal de la cuna es idéntico al que aparece en la xilografía de Juan de Brocar y viene a definir las dos primeras edades de la infancia: «HEV IACET IN GREMIO TETRE CALIGINIS INFANS IGNARVS RERVM NESCIVS IPSE SVI», es decir: «^Ay! En el regazo 

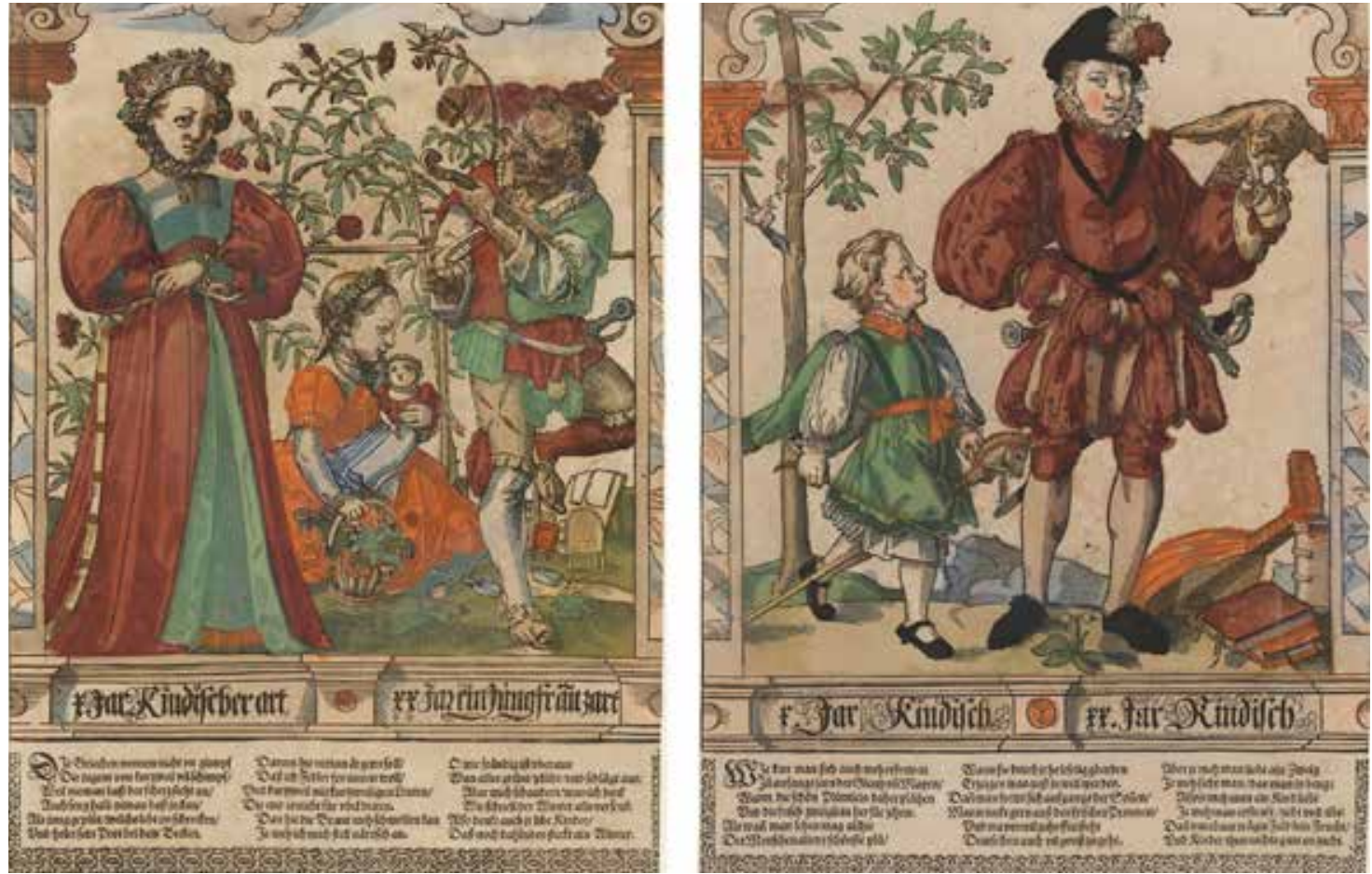

Figura 15.

Tobias Stimmer, 1575-1577. Izquierda: «Niña de X años y virgen de XX» [f. 1], en: Las diez edades de las mujeres. Derecha: «Niño de X años y adolescente de XX» [f. 1], en: Las diez edades de los hombres. Xilografía y acuarela sobre papel, 35,4 x 27,4 cm. Halle an der Saale, Grafische Sammlung, Moritzburg Kunstmuseum, MOIIG00046 y MOIIG00051.

de esta nebulosa penumbra [que es la infancia], el niño ignora todo sobre el mundo y sobre sí mismo».

Tanto en la xilografía de Honcala como en el óleo anónimo posterior, el camino todavía no se ha bifurcado para escenificar el porvenir del niño, lo que significa que su alma es aún un enigma. Sus pasatiempos contienen en ciernes todas las potencialidades de la mente, las buenas y las menos buenas. Sin embargo, en este lienzo, el pintor ha suprimido el molinillo de juguete, dejando solo el pájaro atado en manos de la niña. En las de su acompañante masculino, reconocemos la tablilla de lectura con un utensilio para escribir o bien algún tipo de carraca o sonajero - aunque esta segunda opción parece menos probable, a juzgar por el grabado original-. He aquí, pues, una nueva alegoría moralizante de las edades que ofrece a las novicias y religiosas del convento salmantino un testimonio de la vía que han elegido, la de la consagración a Dios, que debía conducir, con perseverancia, a la salvación.

La alusión al pájaro reaparece en Les quatre âges de l'homme, pintura caravagista de Valentin de Boulogne (c. I627-1629) $)^{82}$. Un niño ensimismado, un joven tocando el laúd, un soldado adormecido con barba y armadura y un viejo bebedor. El infans lleva en las manos una jaula de madera. Pero, a diferencia de las obras ante- riores, el muchacho ha dejado escapar a su «juguete volador», símbolo de la vacuidad del aire y de la ingenuidad propia de la primera edad. Con la jaula abierta lo representa también Daniël Heinsius en uno de sus célebres emblemas de $1616^{83}$. La división en cuatro edades escogida por De Boulogne cobró fuerza en el siglo XVII gracias a la Iconologia, de Cesare Ripa (I 593), que pronto se convirtió en la mayor fuente de inspiración para temas alegóricos ${ }^{84}$.

Por aquellos años, otra nueva arquitectura de las edades se difundió por el territorio de los Augsburgo gracias al trabajo de los talleres de grabado. Nos referimos a las "pirámides» o «escaleras de la vida». Uno de los ejemplos más tempranos es la xilografía realizada en I 530 por Jörg Breu hijo a partir de un dibujo previo atribuido a Hans Holbein el Joven ${ }^{85}$. En una reimpresión de i 540 conservada en el Museo Británico ${ }^{86}$ podemos apreciar una escalera de nueve peldaños y nueve nichos que simbolizan nueve edades del hombre y nueve animales correspondientes. En el horizonte se alza una imagen del Juicio Final con la Virgen y san Juan Bautista como prodromos. Breu deja claro que el ser humano comienza su camino en la cuna, ascendiendo hasta la madurez, para luego descender hasta el sepulcro. No hay nada nuevo en la elección del caballito de juguete como símbolo de los placeres de la infancia y de su «fantasía irra- 
cional». Este último aspecto queda reforzado por la asociación del niño con el macho cabrío. Además, el niño se enfrenta a la amenaza de la Muerte, apostada en la cúspide de la escalera. La mirada hueca del esqueleto se cierne sobre él, dando a entender que podría disparar su flecha en cualquier momento. Por tanto, el ciclo de las edades se entronca aquí con la danza macabra o Totentanz, otro de los grandes imaginarios gestados durante el otoño de la Edad Media.

De nuevo, un grabado sirve de modelo para una pintura realizada años después. El pintor holandés Cornelius Saftleven ejecutó una pequeña tabla al óleo destinada a una casa noble de Rótterdam. En ella representa una escalera de la vida con nueve peldaños como la de Breu. Esta vez sin animales y con diez edades a intervalos de diez años (figura I4). El infans situado al pie de las gradas sostiene una vara imprecisa y el puer de diez juega con un aro: un juguete que también resulta novedoso. Grabadores holandeses posteriores, como Jan Baptist $\mathrm{Mu}-$ $y_{k e n s}{ }^{87}$, se inspirarán a su vez en este modelo para difundir sus propias versiones mediante calcografías. Cabe destacar que la mayoría fueron fieles al modelo de Breu y Saftleven en lo relativo a las edades adultas, pero no así en las correspondientes al infans y el puer, en las que cada grabador y su taller modificaban a voluntad el tipo de juguete o atributo, dando lugar a una constelación de ejemplos.

Por último, en la Alemania luterana también comenzó a circular la serie Die zebn Lebensalter von Mann und Frau, concebida por el pintor y grabador suizo Tobias Stimmer y estampada por Bernard Jobin entre I 575 y I $577^{88}$. Representa la vida humana en diez edades separadas por sexos. Los personajes están ataviados a la moda estrasburguesa de la época. Cada imagen presenta dos edades, al pie de la cual se añaden unos versos del autor satírico Johann Fischart, con el fin de interpretar cada figura; a modo de emblema. En el caso del varón (figura is derecha), su primera infancia - hasta los diez añosestá marcada por los juegos que simulan la vida adulta, simbolizados por el caballito de palo y la fusta. El texto define al niño como un ser que todavía no está preparado para el mundo ${ }^{89}$. Junto a él surge un apuesto mozo. En esta segunda edad - hasta los veinte años - el joven es Rindish ('cabeza hueca') como una res y víctima de un temperamento despreocupado y sanguíneo. La comparación nos recuerda aquella que Clara Hätzlerin introdujo en su Liederbuch de I47I, la fuente más antigua de habla germana que relaciona las diez edades del hombre con diez animales y, en concreto, al joven de veinte años con un ternero, como en la xilografía de Jörg Breu ${ }^{90}$. Hay que añadirle el atributo del halcón. Esta

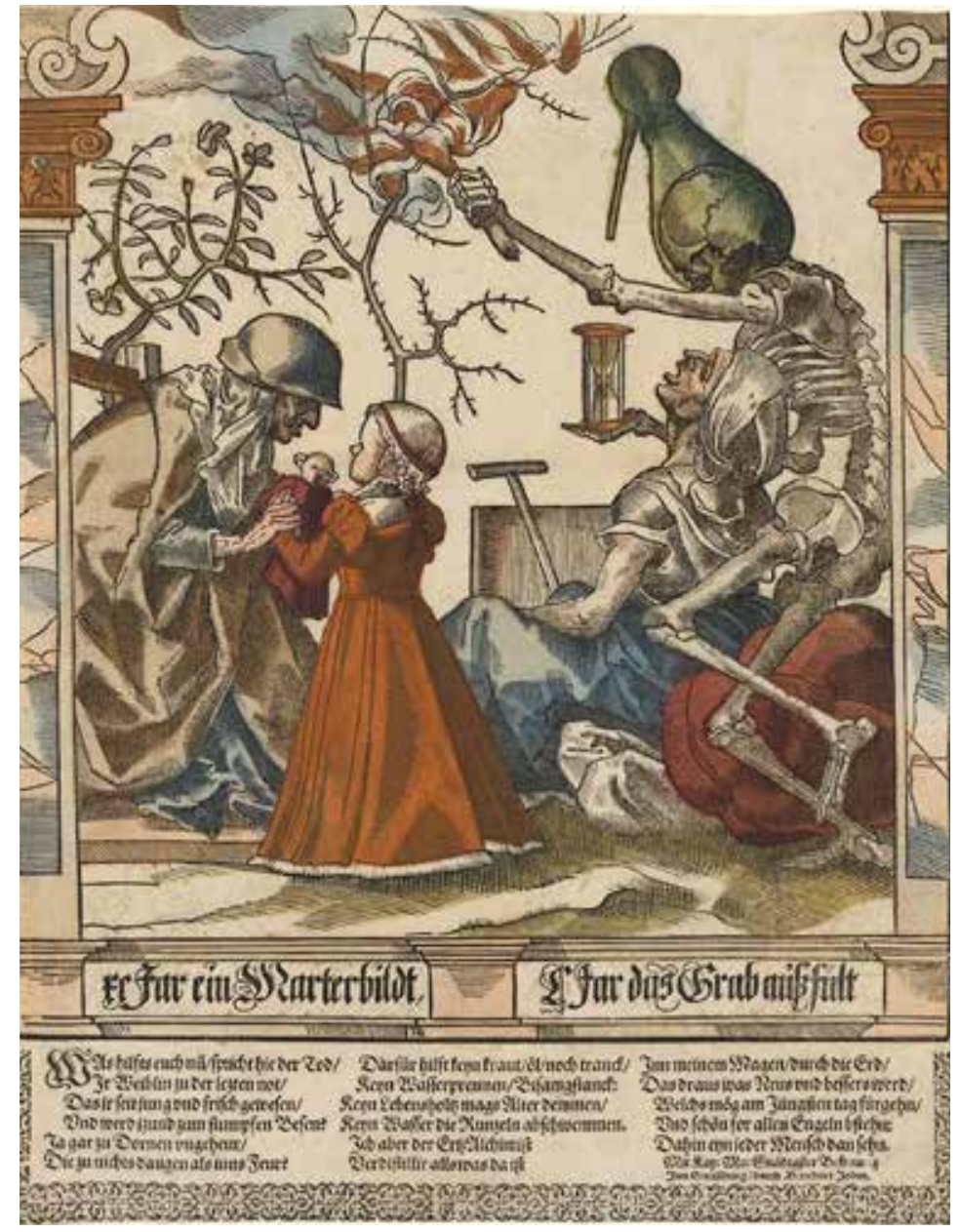

Figura 16.

Tobias Stimmer, «La anciana de XC años, la niña, la tumba de la anciana de $\mathrm{C}$ años y la Muerte» [f. 5], en: Las diez edades de las mujeres, 1575-1577. Xilografía y acuarela sobre papel, 35,4 x $27,4 \mathrm{~cm}$. Halle an der Saale, Grafische Sammlung, Moritzburg Kunstmuseum, MOIIG00050.

vez el pájaro no tiene ni cuerda ni jaula, pues, si recuerda los juegos viriles de la cetrería y la caza, también expresa la idea de alzar el vuelo típica de la adolescencia.

En el emblema de la primera edad femenina, Stimmer introduce la imagen de una niña jugando con su muñeca (figura is izquierda) ${ }^{91}$. Desde el fresco de Guariento y los manuscritos posteriores de Padua y Módena no habíamos vuelto a encontrar este juguete en el ciclo de las edades. Stimmer detalla la muñeca, que va adornada con un collar de perlas y una diadema. Su aspecto parece anticipar el de la joven que se alza junto a la niña. Se trata de una virgen de veinte años vestida con joyas nupciales. Ella parece más prudente y madura que el muchacho del halcón. La mirada comedida y las manos colocadas sobre el vientre aluden al estereotipo del recato sexual propio de la aristocracia. Sin embargo, las aves en celo posadas en lo alto del rosal indican claramente su futuro. Al mismo tiempo, un sospechoso rascatripas se le acerca con intención 

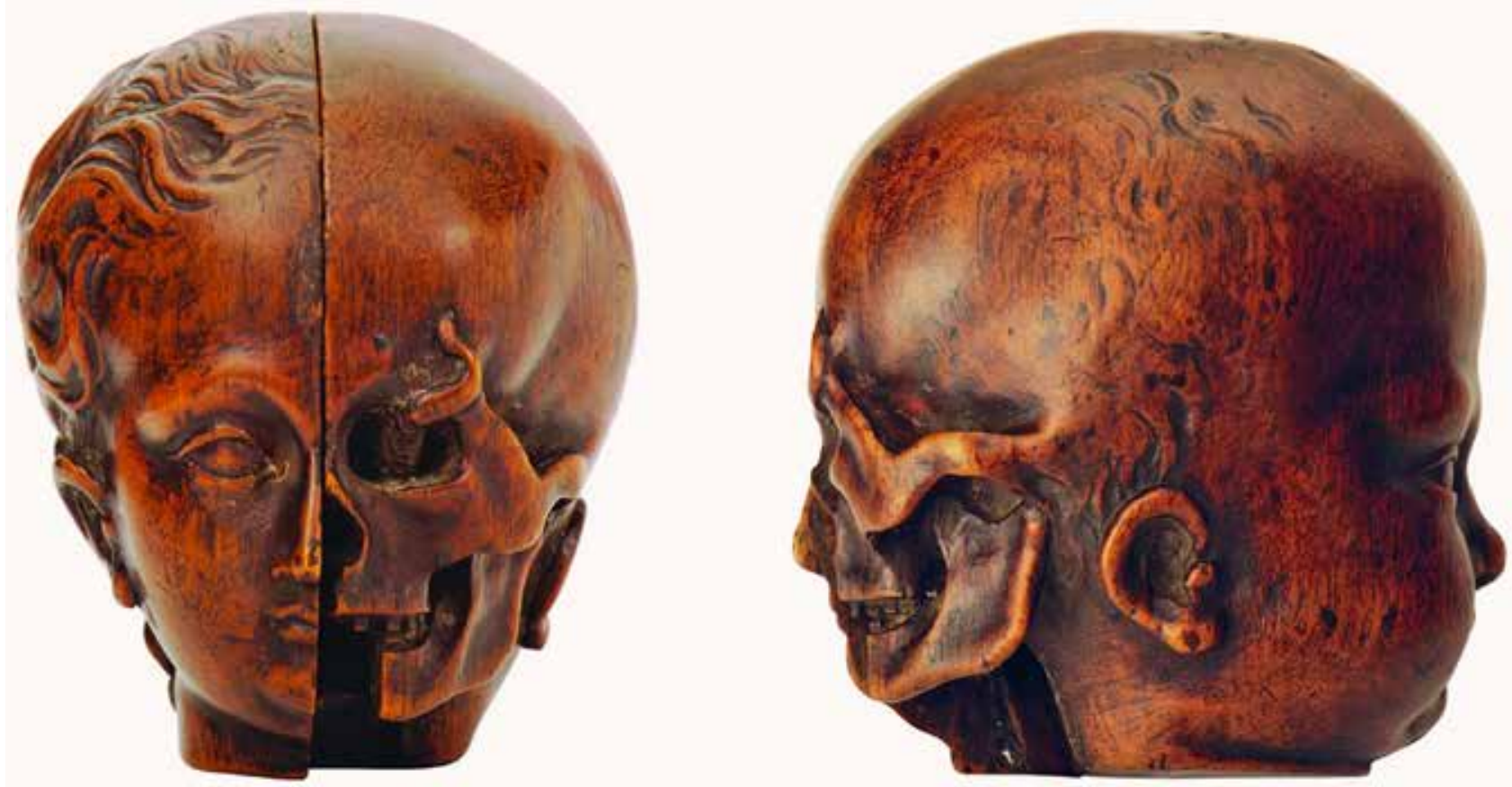

Figura 17.

Anónimo holandés, Memento Mori, de Viererkopf, ca. 1650. Madera de boj, 6 x 5,5 x 6,1 cm. Hamburgo, Museum für Kunst und Gewerbe, 1962.58.a, b.

de seducirla ${ }^{92}$. Es la Muerte disfrazada de bardo bailarín, de bruñida tez, aguileña, orejas un tanto afiladas y sonrisa diabólica, que le canta:

$¡ \mathrm{O}$, qué gozo tan grande sentimos cuando

[florece la primavera!

Mas espanto invádenos al divisar cuán presto [cae la edad invernal.

Recuerda, niña amada, que el invierno

[también de ti hará calavera ${ }^{93}$.

«Recuerda muchacha, que si persigues los placeres de una vida disipada y pierdes tu honra y tu virginidad, vendré para llevarte al Infierno.» Al llegar al último de los emblemas, Stimmer cierra el círculo de la vida humana personificándolo en dos ancianas acompañadas de una niña y un esqueleto (figura I6) ${ }^{94}$. Los versos dedicados a esta edad comparan a la mujer con un rosal, del cual solo quedan las espinas. A la izquierda de la imagen, la anciana de noventa años se inclina hacia la niña con gesto grave. $\mathrm{Pa}$ rece advertirle de su destino final sujetando sus manos. Pero en ellas vemos de nuevo una muñeca. Sin menoscabo del memento mori, la anciana acaso trata también de persuadir a la niña para que aproveche su infancia, con sus juegos y sus juguetes, pues esa dulce edad pasará pronto para no volver. La mitad derecha de la estampa nos muestra a la Muerte con el cráneo metido en un atanor de alquimista. En su mano izquierda muestra una tea encendida, y en su diestra, un reloj de arena junto a la anciana, que aparece ahora con la boca abierta, exhalando su último aliento. Su advertencia se ha cumplido.

Este último ciclo y la xilografía de Breu dieron paso a numerosas Vanitas relacionadas con la Danza de la Muerte, al igual que piezas de gabinete como el Memento Mori, de Viererkopf. Realizado por un escultor neerlandés, la pequeña talla presenta cuatro cortes longitudinales de la cabeza pertenecientes a distintas edades (el niño, el hombre, la mujer y la calavera), con sus combinaciones respectivas. La primera y la última muestran la posición «infancia-muerte» (figura 17 ), recogiendo así la idea de que el comienzo de la vida es también el primer paso hacia su término. A esta imagen le corresponde la del homo bulla est ${ }^{95}$, representando, por lo general, a un putto o cupido candoroso jugando con pompas de jabón. Dicha alegoría nos habla por igual del poder destructivo del tiempo y de la fragilidad de la vida y del amor, que se desvanecen como burbujas de jabón, aunque el tema del niño burbuja, surgido en el siglo XVI, bien valdría un estudio particular.

En definitiva, los diversos programas iconográficos de las Ætates hominum fructificaron en toda clase de soportes visuales y adquirieron formas simbólicas cada vez más complejas gracias a los textos de los humanistas del Renacimiento. Las obras resultantes revelan una conexión evidente con las fuentes de la Antigüedad, que actuaron como matriz conceptual. Sin embargo, también existe una diferencia radical entre ambos modelos: la literatura pagana ponía el acento en la evolución biológica del hombre, concebida como 
mero crecimiento y declive, mientras que los autores católicos insistirán en la historia de la Salvación, buscando imágenes que enseñen una forma de ascenso hacia Dios en cada una de las edades. Como consecuencia, la imagen del niño y sus juegos adquirió un valor espiritual desconocido para el mundo griego y romano. De este modo, los juguetes se convirtieron en portadores de un cierto valor moral, no siempre negativo. El juego y los juguetes infantiles podían resultar un medio de perfeccionamiento siempre y cuando no diesen rienda suelta a los más bajos instintos del niño, tales como la ira, la obstinación, el deseo desenfrenado de posesión y las fantasías idolátricas. En territorio católico, los juegos infantiles no contradicen el libre albedrío del alma. En cambio, los autores y los artistas protestantes verán en la iconografía alegórica del juguete un signo predeterminado de la bondad o la maldad del niño, imposible de romper o de invertir, de acuerdo con la teoría de la doble predestinación calvinista.
En la España de la Contrarreforma, los caminos de la perdición y de la salvación, con su exaltación de la libertad de elección por parte del niño, darán paso a los Emblemas morales, de Sebastián de Covarrubias ( 16 Io), destacando la antigua relación entre juego, infancia y locura, basada en el modelo de santo Tomás y en el de Erasmo. Por otro lado, tanto en los territorios protestantes como en los reinos católicos, la moral cristiana se entrelazará con la ética estoica grecolatina para desembocar en la iconografía de la Tabla de Cebes o Pinax. Se trata de un documento alegórico de origen griego sobre la vida humana que fue traducido a las principales lenguas vernáculas desde principios del siglo XVI e impreso por toda Europa. En estas imágenes, el niño y sus juguetes, situados en las murallas exteriores de la montaña de la Sabiduría, encarnan el tema clásico de la elección moral entre el vicio y la virtud. Pero esta es ya otra historia que merece ser contada en otra edad. 
1. J. Marías (1961), «El método histórico de las generaciones», $R e$ vista de Occidente, p. 9-20, 30.

2. R. Guardini (1953), Die Lebensalter: Ibre ethische und pädagogische Bedeutung, Würzsburg, Werkbund, 1967, versión española: Las etapas de la vida: Su importancia para la ética y la pedagogía, Madrid, Palabra, 1997, p. 148.

3. R. Fossier (2010), The Axe and the Oath: Ordinary Life in the middle ages, Princeton University Press, p. 37-144; J. A. Burrow (1986), The Ages of Man: A Study in Medieval Writing and Thought, Oxford, Clarendon Press; M. Dove (1986), The Perfect Age of Man's Life, Cambridge, Cambridge University Press; E. SEARs (1986), The Ages of Man: Medieval Interpretations of the Life Cycle, Princeton University Press; M. E. Goodich (1989), From Birth to Old Age: The Human Life Cycle in Medieval Thought, 1250-1350, Lanham-Maryland, University Press of America, y R. R. SEars y S. S. Feldman (eds.) (1964), The Seven Ages of Man, Los Altos, W. Kaufmann, p. 5-18, 35.

4. M. Martínez (1748), «Conversacion Sexta: Que sean las edades, y quantas?», Medicina Sceptica y Cirugia moderna con un tratado de operaciones chirurgicas, Madrid, Imprenta Real, p. 69.

5. E. Becchi y D. Julia (eds.) (1998), Histoire de l'enfance en Occident, París, Seuil; D. LeTt (1997), L'Enfant des miracles: Enfance et société au Moyen Âge (XIIe-XIIIe siècle), París, Aubier, y H. Cunningham (1995), Children and Childhood in Western Society since 1500, Nueva York, Langman.

6. O. Vaz-Romero Trueba y M. Manson (2018), «Toys in Spanish Art (15th-19th Centuries): Iconographic Languages», en Luísa Magalhães y Jeffrey Goldstein (eds.), Toys and Communication, Nueva York, Palgrave, p. 91-115, y M. Manson (2005-2006), «Histoire du jouet dans l'art, approche anthropologique, 1450-1650", Annali della Facoltà di Lettere e Filosofia, Università di Siena, 2627, p. 129-164.

7. Apud Diógenes Laercio, Pitágoras, VIII, 10.

8. Apud Ovidio, Metamorfosis, XV, 199-202.

9. M. Horstmanshoff (ed.) (2010), Hippocrates and Medical Education, Leiden-Boston, Brill, y J. JouAnNa (2005), «La tradition des quatre humeurs et des quatre tempéraments dans la tradition latine (Vindicien, Pseudo-Soranos) et une source grecque retrouvée)», Revue des Études Grecques, 118, p. 138-167.

\section{Apud Varron, De lingua} latina, V, 165; Tertuliano, De Anima, 56, 6, y J.-P. NÉrAUdeAU (1976), La Jeunesse dans la littérature et les institutions de la Rome républicaine, París, Les Belles Lettres, p. 91-96, 124-143.

11. G. M. A. Hanfmann (1951),

The Season Sarcophagus in

Dumbarton Oaks, Cambridge,

Harvard University Press.

12. L. BRISON (1996), Introduction à la philosophie du mythe, París, Vrin, v. 1, p. 184-185.

13. Apud Ptolomeo, Tetrabiblos, IV, 10.

14. R. van MARLe (1932), Iconographie de l'art profane au MoyenÂge et à la Renaissance et la décoration des demeures (Allégories et symboles), La Haya, M. Nijhoff, v. 2 , p. 153.

15. Apud Guillermo de Conches, De philosophia mundi, IV, 17.

16. A. Paravicini (2003), «Edades de la vida», en Diccionario razonado del Occidente medieval, dirs. J. Le Goff y J.-C. Schmitt, trad. de A. I. Carrasco Manchado, Madrid, Akal, p. 245.

17. Apud Alberto Magno, De Aetate, I, 2.

18. Apud Philippe de Novare, Quatre ages de l'homme, II, 56.

19. Apud Agustín de Hipona, De Diversis quaestionibus ad Simplicianum, LXXXIII, 58, 2, 64; De Genesi contra manichaeos, I, 36-39, 42, y De Civitate Dei, XXII, 30 y $\mathrm{X}, 14$.

20. Infantia hasta los siete años, pueritia hasta los catorce, adolescentia hasta los veinticuatro años. Isidoro de SEvilla, Etymologiarum, V, XXXVIII, 3-5, XI, II, y Differentiae, II, XIX, y R. L. Overstreet (2009), «The Greek Concept of the 'Seven Stages of Life' and its New Testament Significance», Bulletin of Biblical Research, 19 (4), p. 537-563.

21. G. Ashby (1982), «Une analyse stylistique des formules épiques contenant 'enfant' ou l'un des synonymes», en L'Enfant au Moyen
Âge: Littérature et Civilisation. Sénéfiance, 9, p. 219; L. Paterson (1989), «L'Enfant dans la littérature occitane avant 1230", Cabiers de civilisation médiévale, 32, p. 237; P.-A. Sigal (1982), «Le Vocabulaire de l'enfance et de l'adolescence dans les recueils de miracles latins des XIIe et XIIIe siècles», L'Enfant au Moyen Âge..., p. 141-160, y P. Riché (1973), Éducation et Culture dans l'Occident barbare (VIe-VIIIe siècles), París, Seuil, p. 500.

\section{J. Cejador Frauca (1996),} Vocabulario medieval castellano, Zúrich, Nueva York, G. Olms, p. 286.

23. P. Riché y D. Alexandre-BiDON (1994), L'Enfance au Moyen Âge, París, BnF-Seuil, p. 16.

24. Aldobrandino de Siena (1256), Regimen corpus, y L. LANDOuzy y R. PÉPIN (1911), Le régime du corps de maitre Aldebrandin de Sienne, París, Champion, p. 75.

25. Tomás de Aquino, Summa Theologiae, III, Q. 68, art. 12, y D. LeTT (1988), «L'enfance: Aetas infirma, aetas infima», Médiévales, 15, p. 90-91.

26. Sirva como ejemplo el cuerpo normativo de la Corona de Castilla: Las Siete Partidas, ley xxvir.

27. Maria J. Gallofré (ed.) (1984), Ramon Llull: Llibre d'Evast e Blanquerna, Barcelona, Edicions 62, p. 26.

28. M. de Fréville (1888), Les Quatre Âges de l'Homme: Traité moral de Philippe de Novarre, París, Didot, p. 14.

29. O. Vaz-Romero Trueba (2016), «Puer Senex o el niño en la pintura del Greco y de sus contemporáneos españoles, entre neoplatonismo y naturalismo", en El Greco en su IV Centenario: Patrimonio hispánico y diálogo intercultural, dir. E. Almarcha Núñez-Herrador et al., Toledo, UCLM, p. 907-930.

30. Apud Juan Crisóstomo, Homilía LXXXI sobre el Evangelio de Juan [17, 6-13], 3.

31. Apud Agustín de Hipona, Confessiones, I, VI, 7-10, VII, 1112, X, 16, XIX, 30, y Civitate Dei, XXI, 14.

32. Confessiones, I, 19.

33. D. LeTt, «L'enfance: Aetas infirma, aetas infima», op. cit., p. 95. 
34. S. LebecQ (1990), «La famille et les apprentissages de Liudger d'après les premiers chapitres de la Vita Liudgeri d'Altfrid», en Haut Moyen Âge: Culture, Éducation et Société. Études offertes à Pierre Riché, dir. M. Sot, París, Érasme, p. 295.

35. D. LeTT, op. cit., p. 96.

36. A. Fourrier (ed.) (1972), Jean Froissart: L'Espinette amoureuse, París, Klincksieck, p. 53-55.

37. Ratis Raving, I, v. 1976-1990, y J. R. Lumby (dir.) (1870), Ratis Raving, and other moral and religious pieces, Londres, Trübner, p. 57-58.

38. Luís de Góngora, Hermana Marica, v. 43-60; cf. J. V. SALIDO (2014), «El mundo infantil en el romancero hispánico barroco: Educación, juegos y folclore», Ocnos: Revista de Estudios Sobre Lectura, 11, p. 141-168, y A. Pelegrín (1998), Repertorio de antiguos juegos infantiles: Tradición y literatura hispánica, Madrid, CSIC, p. 280-281, 302-304.

39. O. Vaz-Romero Trueba (2018), «La Naturaleza en juego: Poéticas del juguete artesanal en el arte europeo», en Poètiques de la natura: Espais per a l'espiritualitat, dirs. M.-T. Sala García, y I. Gras Valero, Barcelona, Universidad de Barcelona, p. 65-88.

40. Nueva York, The Morgan Library \& Museum, M.6 f. 40v.

41. E. C. Rouse y A. Baker (1955), «The Wall-Paintings at Longthorpe Tower, near Peterborough, Northants", Archaeologia, 96, p. 10, 33, 43-44, figura 3, y A. EMERY (2006), Greater Medieval Houses of England and Wales, 1300-1500: Southern England, Cambridge, Cambridge University Press, p. 475.

42. H. Meyer (1988), «Bartholomäus Anglicus, 'De proprietatibus rerum': Selbstverständnis und Rezeption», Zeitschrift für deutsches Altertum, 99, p. 237-274, y E. VoIGT (1910), «Bartholomaeus Anglicus De proprietatibus rerum: Literarhistorisches und Bibliographisches», Englische Studien: Organ für englische Philologie, 41, p. 337-359.

43. E. SEARs, The Ages of Man..., op. cit., p. 134-155.

44. Londres, British Library (= BL), Royal 6 E. VII, f. 67v.

45. París, Bibliothèque nationale de France (= BnF), Fr. 22532, f. 84v; Fr. 9141, f. 98; Fr. 22531, f. 99v, y Fr. 218, f. 95r. Cf. Oxford, Bodleian Library, Douce 8, f. 6r.

46. F. Avril y N. Reynaud (1998), Les Manuscrits à peinture en France (1440-1520), París, BnF, Flammarion, p. 172.

47. Ciudad del Vaticano, Biblioteca Apostólica, Pal. lat. 291, f. 68r.

48. Cambridge, Fitzwilliam Museum, ms. 330, f. 41r.; Roma, Biblioteca Casanatense, ms. 1404, f. 4v., y Londres, Wellcome Institute for the History of Medecine, ms. 49, f. 30v.

49. De Lisle Psalter (ca. 1310), BL, Arundel 83 (II), f. 126v., y M. Dove, The Perfect Age of Man's Life..., op. cit., p. 90.

50. Siena, Biblioteca Comunale degli Intronati, T IV 7, f. 73v.

\section{Horacio, Satirae II, 3, 248.}

52. A. M. Spiazzi (1991), Chiesa degli Eremitani a Padova, Milán, Electa, y A. Moschetтi (1934),

La Cappella degli Scrovegni e la Chiesa degli Eremitani a Padova, Milán, Treves, p. 26.

53. A. Boczkowsкa (1977), «The Crab, the Sun, the Moon and Venus: Studies in the Iconology of Hieronymus Bosch's Triptych 'The Garden of Earthly Delights'», Oud Holland, 91 (4), p. 197-231, y W. Deonna (1954), «The Crab and the Butterfly: A Study in Animal Symbolism", Journal of the Warburg and Courtauld Institutes, 17 (1-2), p. 47-86.

54. El pésimo estado de conservación obedece a los graves daños sufridos tras el terremoto de 1832, los bombardeos de 1944 y un nuevo terremoto que sacudió a la región de Umbria y Las Marcas en 1997.

55. C. Galassi (ed.) (2001), Palazzo Trinci, Perugia, Comune di Foligno, p. 28.

56. M. Caciorgna (2001), «Sanguinis et belli fusor: Contributo all'esegesi dei tituli di Palazzo Trinci (Loggia di Romolo e Remo, Sala delle Arti e dei Pianeti, Corridoio)», en Palazzo Trinci di Foligno, dirs. G. Benazzi y F. F. Mancini, Perugia, Quattroemme, p. 401-426.

57. C. Galassi (1991), «Arti liberali, pianeti, età dell'uomo, ore del giorno nella 'Camera delle Rose' di Palazzo Trinci: La metafora del tempo che passa in un ciclo pittorico degli inizi del Quattrocento»,
Bollettino dei monumenti musei e gallerie pontificie, 15, p. 35-50.

58. J. Cardigni (2016), «Presencias herméticas en De nuptiis Mercurii et Philologiae de Marciano Capela», Anales de Historia Antigua, Medieval y Moderna, 50, p. 37-53.

59. P. D’Ancona (1902), «Le rappresentazioni allegoriche delle Arti liberali nel Medio Evo e nel Rinascimento», L'Arte, 5, p. 139.

60. M. SAlmi (1919), «Gli affreschi del palazzo Trinci a Foligno», Bolletino d'arte, 13, p. 175.

61. C. Bertelli (1969),

«L'enciclopedia delle Tre Fontane», Paragone, 20, p. 24-49.

62. G. S. Aronow (1985), A Documentary History of the Pavement Decoration in Siena Cathedral, 1362 through 1506, Columbia University, Ann Arbor, p. 437-438.

63. Pr. 7, 6.

64. Eclo. 7, 25.

65. Patrologia Latina, CLXXII, 633BD.

66. M. Caciorgna y R. Guerrini (2013), Il Pavimento del Duomo di Siena, Milán, Silvana, p. 130.

67. Bernardino de Siena, Prediche, 37,38 .

68. Mt 2, 16-18.

69. R. H. H. Cust (1906), The Pavement Masters of Siena, 13691562, Londres, G. Bell, p. 62, pl. xII.

70. M. Manson (2006-2008), «Les jouets du pavement de la Cathédrale de Sienne (1475-1545), et l'originalité de Domenico Beccafumi», en Sacro e profano nel Duomo di Siena, dir. M. Lorenzoni, Siena, Opera dela Metropolitana, p. 238-249.

71. E. Currie (2006), Inside the Renaissance house, Londres, Victoria-Albert Museum, p. 55, y A. W. B. RANDOLPH (2004), «Gendering the period eye: Deschi da Parto and Renaissance Visual Culture», Art History, 27, p. 538-562.

72. O. Rank (1922), Der Mythos von der Geburt des Helden: Versuch einer psychologischen Mythendeutung, Viena, Franz Deuticke, p. 86-88.

73. Plauto, Rudens, IV (4), 111126, y Miles gloriosus, V, 1397-1399. 
74. S. Francolini y M. Vervat (2001), «Il 'Gioco del Civettino' dello Scheggia: Il ritrovamento di un ulteriore dipinto e la tipologia dell'oggetto", Kermes: La revista del restauro, 42, p. 51-63.

75. Ajaccio, Museo Fesch, MFA 852.1.631.

76. «I am called Childhood, in play is all my mind, / To cast a quoit, a cockshy, and a ball. / A top can I set, and drive it in its kind. / But would to god these hateful books all. / Were in a fire burnt to powder small. / Then might I lead my life always in play: / Which life god send me to mine ending day.» R. S. SYLvester (ed.) (1976), Thomas More: The History of King Richard III and Selections from the English and Latin Poems, New Haven, Londres, Yale University Press, p. 114-118.

77. I. Pinchbeck y M. Hewitt (1969), Children in English Society: From Tudor times to the Eighteenth century, Londres, Routledge \& Kegan Paul, v. 1, p. 298.

78. J. Pauli (1535), Schimpff und Ernst: Durch alle Welthändel, Estrasburgo, B. Grieninger, 1535. BnF, Rés.G.Y2 42, f. 49.

79. Madrid: Biblioteca Nacional de España, ms. 6296, f. 7r.

80. Granada, Biblioteca de la Universidad de Granada, A-029-170.
81. G. Parker (2014), Imprudent King: A New Life of Philip II,

New Haven, Yale University Press, fig. 2, p. XII, 11.

82. Londres, National Gallery, NG4919.

83. D. Heinsius (1616), «Ambach van Cupido", en Nederduytsche poemata, Ámsterdam, Janssen, p. 91, pl. 46.

84. C. RIPA (1593), Iconologia overo Descrittione dell'Imagini universali, Roma, Lepido Facij.

85. J. D. Passavant (1860-1864), Le Peintre-Graveur, Leipzig, Weigel, v. 3, p. 381, pl. 31.

86. Londres, Museo Británico (= BM), 1927, 0614.181.

\section{BM, S.5260.}

88. K. BAKE (2005), «Geschlechtsspezifisches Altern in einem Lebensalter-Zyklus von Tobias Stimmer und Johann Fischart», en Alter und Geschlecht: Repräsentationen, Geschichten und Theorien des Alter $(n)$ s, dir. H. Hartung, Bielefeld, TagungsbandUniversität Greifswald, p. 113-133, y U. КосH (ed.) (2002), Zwischen Katheder, Thron und Kerker: Leben und Werk des Humanisten Caspar Peucer 1525-1602: Ausstellung 25. September bis 31. Dezember 2002, Stadt-Museum, Bautzen, Bautzen, Domowina, p. 78-85.
89. U. DrÄGER (2000), Die Güter dieser Welt: Schätze der Lutherzeit aus den Sammlungen der Moritzburg Halle, Halle an der Saale, SGMH, p. 59.

90. «X jar ain kitz, $X X$ jar ain kalb, XXX jar ain stier, XL jar ain leo, $\mathrm{L}$ jar ain fuchs, LC jar ain wolf, LXX jar ain katz, LXXX jar ain hund, LXXXX jar ain esel, C jar ain gans». C. HäTZLERIN (1471), Die zehn Lebensalter, Augsburgo.

91. U. DrägER, Die Güter dieser Welt..., op. cit., p. 58.

92. M. Bendel (1940), Tobias Stimmer. Leben und Werk, Zúrich, Berlín, Atlantis, p. 110.

93. La libre traducción en verso es nuestra y ha sido realizada a partir del original alemán: «O wie fräudig ist vberaus Wan alles Grant / plüht / vnd schläg aus: Aber mich schaudert / wan ich denk Wie schnell der Winter alls versenk: Also denkt auch jr libe Kinder / Daß noch dahinden steckt ain Winter».

94. U. Dräger, Die Güter dieser Welt..., op. cit., p. 33.

95. H. W. Janson (1937), «The putto with the death's head", Art Bulletin, 19, p. 423-449, y cf. W. STECHOw (1978), «Homo bulla», en Art Bulletin, 20, p. 227-228. 